\title{
MURATORI E OS DEFEITOS DA JURISPRUDÊNCIA: CONSIDERAÇÕES SOBRE OS FUNDAMENTOS TEÓRICOS DAS REFORMAS JURÍDICAS SETECENTISTAS
}

\author{
MURATORI AND THE DEFECTS OF JURISPRUDENCE: \\ CONSIDERATIONS ON THE THEORETICAL FOUNDATIONS OF 18TH- \\ CENTURY LEGAL REFORMS
}

\section{MURATORI Y LOS DEFECTOS DE LA JURISPRUDENCIA: CONSIDERACIONES SOBRE LOS FUNDAMIENTOS TEÓRICOS DE LAS REFORMAS JURÍDICAS DE LOS SETECIENTOS}

\author{
ALEXANDER DE CASTRO \\ http://orcid.org/0000-0002-3316-2773 / http://lattes.cnpq.br/8837968472997490 / alexander.decastro@unicesumar.edu.br \\ Centro Universitário de Maringá (UniCesumar) e UniFatecie. \\ Maringá, PR, Brasil.
}

\begin{abstract}
RESUMO
O intuito desse trabalho é fazer um balanço da importância da obra de Lodovico Antonio Muratori para a formação do reformismo jurídico setecentista. Analisam-se as críticas que Muratori faz à ciência jurídica do antigo regime como parte integrante do discurso político sobre a felicidade pública que se difunde a partir da primeira metade do século XVIII e do qual o próprio Muratori foi um importante expoente. Tal discurso, que - porder-se-ia argumentar - mais tarde iria desenvolver-se no sentido de contribuir para a fundamentação dos direitos humanos e da personalidade, foi inicialmente tópico importante da justificação da centralização absolutista. Procura-se demonstrar, assim, a conexão entre a teoria da reforma do direito e os primórdios da formação da ideia de absolutismo esclarecido. Em seguida, explica-se como as ideias de Muratori foram recepcionadas por autores iluministas e, através deles, ganharam toda a Europa, tornando-se parte do repertório comum da crítica ao antigo regime no século XVIII. Por fim, comenta-se a possibilidade de reverberação das ideias de Muratori durante os primórdios das reformas jurídicas pombalinas.
\end{abstract}

Palavras-chave: Defeitos da Jurisprudência. Felicidade Pública. Iluminismo Jurídico. Muratori. Reformismo Jurídico Setecentista.

\begin{abstract}
The purpose of this paper is to take stock of the importance of Lodovico Antonio Muratori's work for the formation of the 18th-century legal reformism. We analyze Muratori's criticism of Ancien Régime legal science as a part of the political discourse on the public happiness that spread from the mid-18th Century, which had Muratori as one of its most important representatives. Said discourse, that later - one could argue - would be developed in a way that contributed to the foundations of human and personality rights, was initially an important topic of the justification of absolutist centralization. We seek to demonstrate the connection between the theory of legal reform and the beginnings of the formation of the idea of enlightened absolutism. Thereafter, we explain how Muratori's ideas were received by Enlightenment authors and, through them, conquered the whole Europe thus becoming part of the common repertoire of Ancien Régime criticism. Finally, we comment on the possible reverberation of Muratori's ideas in the beginning of Pombaline legal reforms in Portugal.
\end{abstract}

Keywords: Defects of Jurisprudence. Public Hapiness. Legal Enlightenment. Muratori. Eighteenth-century legal reformism. 


\section{RESUMEN}

El propósito de este trabajo es hacer un balance de la importancia de Lodovico Antonio Muratori para la formación del reformismo jurídico del siglo XVIII. Analizamos la crítica de Muratori a la ciencia jurídica de Ancien Régime como parte del discurso político sobre la felicidad pública que se extendió desde mediados del siglo XVIII, e que tenía a Muratori como uno de sus representantes más importantes. Dicho discurso, que luego - se podría argumentar - se desarrollaría de una manera que contribuiria a los fundamentos de los derechos humanos y de la personalidad, fue inicialmente un tema importante de la justificación de la centralización absolutista. Buscamos demostrar la conexión entre la teoría de la reforma jurídica y los comienzo de la formación de la idea del absolutismo ilustrado. Despues, explicamos cómo las ideas de Muratori fueron recibidas por los autores de la llustración y, a través de ellas, conquistaron toda Europa y pasaron a formar parte del repertorio común de la crítica de Ancien Régime. Finalmente, comentamos sobre la posible reverberación de las ideas de Muratori al comienzo de las reformas jurídicas pombalinas en Portugal.

Palabras clave: Defectos em la jurisprudencia. Felicidad pública. Ilustración Jurídica. Muratori. Reformismo jurídico del siglo XVIII.

\section{SUMÁRIO}

INTRODUÇAO; 1 FELICIDADE PÚBLICA E SCIENTIA IURIS; 2 OS DEFEITOS DA JURISPRUDÊNCIA E 0 “MERCADO DO FORO"; 3 A CORREÇÃO DOS DEFEITOS DA JURISPRUDÊNCIA E O ABSOLUTISMO; 40 ILUMINISMO: RADICALIZAÇÃO TEÓRICA DO REFORMISMO JURÍDICO; 5 A PRÁTICA DAS REFORMAS JURÍDICAS SETECENTISTAS: O EMBLEMÁTICO CASO DE PORTUGAL; CONCLUSÃO; REFERÊNCIAS.

\section{INTRODUÇÃO}

A história cultural e intelectual do reformismo jurídico setecentista tem muitas vezes enfocado o caráter cosmopolita e transnacional dos fundamentos teóricos das reformas, enfatizando a intensa circulação de ideias na "república das letras" europeia (com importantes reverberações nas Américas). ${ }^{1}$ Conquanto o cosmopolitismo seja um traço distintivo dos intelectuais que se colocaram na vanguarda da construção teórica das reformas setecentistas, as origens locais baseadas em experiências singulares durante a formação do pensamento reformista tiveram papel determinante.

Não se trata, entretanto, de uma contraposição entre cosmopolitismo e localismo, visto que esses impulsos marcadamente regionais acabavam se encontrando em um âmbito superior de síntese que se formou ao longo, sobretudo, dos anos 60 e 70 e que foi responsável pela relativa uniformidade dos fundamentos filosóficos do pensamento reformador do século das luzes.

\footnotetext{
1 É exatamente a partir dessa perspectiva que se desenvolve a clássica Crítica e Crise de Koselleck. Vejase KOSELLECK, Reinhart. Crítica e crise. Tradução de Luciana Villas-Boas Castelo-Branco. Rio de Janeiro: UERJ/Contraponto, 1999.
} 
Trata-se, ao contrário, apenas de resgatar o impacto que motivos e questões atinentes a experiências particulares de reformismo jurídico exerceram sobre os primeiros passos de temas e linhas de pensamento que ganhariam o continente. Nesse sentido, um dos grandes polos de gestação de ideias destinadas a entrar nos cânones reformistas dos setecentos foi o norte da Itália sob a administração do absolutismo esclarecido habsburgo. É ali que se encontra a grande geração de filósofos iluministas dos anos 60 que, principalmente com Cesare Beccaria, daria valiosa contribuição à formação do ideário jurídico reformista do século XVIII.

Entretanto, os primórdios do reformismo jurídico norte-italiano são mesmo anteriores ao iluminismo milanês. Seu mais destacado pioneiro foi Lodovico Antonio Muratori ${ }^{2}$ (1672-1750). Muratori nasceu e transcorreu a maior parte de sua vida no Ducado de Módena e Régio, um território do Sacro Império Romano que gozava, porém, de grande autonomia. Ordenado padre em 1695, Muratori dedicar-se-ia, a partir de certo ponto e pelo resto de sua maturidade intelectual, cada vez mais intensamente à causa das reformas e à elaboração de seus fundamentos teóricos. Essa circunstância o levou a ser classificado entre os expoentes de um iluminismo moderado e católico. ${ }^{3}$

Entretanto, essa afirmação dificilmente poderia ser considerada correta em seu sentido estrito. É verdade que Muratori era adepto de um método racionalista. Todavia, esse racionalismo - que era aplicado, sobretudo, a pesquisas eruditas de índole histórica e filológica sobre textos da história eclesiástica e civil - era certamente muito mais próximo da tradição humanista do renascimento, ainda que em uma versão modernizada pela influência da filosofia seicentista. ${ }^{4}$ De qualquer forma, não se tratava ainda daquele uso amplo da "razão" transformada em ponto de referência geral, esquema onicompreensivo e bandeira ideológica para confrontos políticos, como ocorreu décadas mais tarde.

Ao contrário, ainda que estivesse convencido dos progressos conseguidos com o uso da razão “científica” e com o recurso à experimentação por oposição ao dedutivismo da abstrata dialética escolástica, Muratori no fim ainda temia as consequências de uma confiança exagerada

\footnotetext{
${ }^{2}$ Frequentemente também grafado como Ludovico Antonio Muratori.

${ }^{3}$ Nesse sentido, no contexto da análise da reverberação das ideias de Muratori em Portugal, veja-se SANTOS, Cândido dos. "Matrizes do Iluminismo católico da época Pombalina." In: SILVA, Francisco Ribeiro da. Estudos em Homenagem a Luís António de Oliveira Ramos. Volume I. Porto: Faculdade de Letras da Universidade do Porto. 2004. pp 949-956. p. 955, e COSTA, Mário Júlio de Almeida; MARCOS, Rui de Figueiredo. A reforma pombalina dos estudos jurídicos. In: ARAÚJO, Ana Cristina (Org.). O Marquês de Pombal e a Universidade. Coimbra: Imprensa da Universidade, 2000, pp. 97-125. p. 97.

${ }^{4}$ Sobre o método racionalista de Muratori, veja-se WOOLF, Stuart J. et al. Storia d'Italia. Vol. 3: Dal primo Settecento all'Unità. Torino: Giulio Einaudi editore, 1978, pp. 59-60.
} 
na razão humana. ${ }^{5}$ Mas esse seu racionalismo comedido bastava já, todavia, para dar aos escritos de Muratori um caráter crítico com relação a certos valores da tradição, uma abertura às inovações teóricas que vinham do estrangeiro e, principalmente, uma disposição a ver nas pequenas mudanças e prudentes reformas possíveis soluções aos problemas de seu tempo. Portanto, ao invés de um "iluminista" propriamente dito, Muratori seria mais propriamente descrito como um "reformador esclarecido"6 ou ainda um reformador pré-iluminista. ${ }^{7}$

Muratori construiu uma longeva carreira intelectual, escrevendo proficuamente sobre a história italiana, especialmente medieval. Dentre suas obras históricas, destaca-se, sobretudo, sua monumental Annali d'Italia. Longe de fazer um balanço geral de sua imensa obra, se irá concentrar apenas em tentar entender alguns aspectos de sua contribuição para a formação do ideário jurídico reformista do século XVIII.

Assim, ficará talvez mais claro que as ideias jurídicas das gerações de iluministas italianos, como Cesare Beccaria ou Pietro Verri, longe de serem apenas consequências teóricas da recepção de ideias estrangeiras e da participação de seus autores na cosmopolita república das letras, eram também, ao menos parcialmente, o resultado do desenvolvimento de uma reflexão autóctone anterior. ${ }^{8}$

\section{FELICIDADE PÚBLICA E SCIENTIA IURIS}

A obra de maturidade de Muratori é marcada por dois grandes temas interconectados, quais sejam a crítica à ciência jurídica de então e a questão da felicidade pública. 0 discurso da felicidade pública aparece na literatura política da primeira metade do século XVIII como reflexo teórico da hegemonia pró-absolutista que então se formava e que se baseava sobre a aliança entre príncipes autocráticos e setores sociais emergentes, como a burguesia e a baixa nobreza. Esse discurso político consistia fundamentalmente em atribuir ao soberano o dever de

\footnotetext{
${ }^{5}$ WOOLF, Stuart J. et al. Storia d'Italia. Vol. 3: Dal primo Settecento all'Unità. Torino: Giulio Einaudi editore, 1978, p. 61.

${ }^{6}$ Nas palavras de Daniela Frigo, Muratori era representante de um pensamento "illuminato" mais do que propriamente "illuminista". Veja-se FRIGO, Daniela. Principe, Giudici, Giustizia: Mutamenti Dottrinali e Vicende Istituzionali fra Sei e Settecento. In: COLAO, Floriana; BERLINGER, Luigi (Org.). Illuminismo e Dottrine Penali. Milano: Giuffrè, 1990, pp. 3-38, p. 19.

${ }^{7}$ Sobre Muratori e o pré-iluminismo veja-se FALCO, Giorgio. L. A. Muratori e il preilluminismo. In: FUBINI, Mario. La cultura illuministica in Italia. Torino: ERI, 1957, pp. 23-41.

8 Para Daniela Frigo, Muratori é justamente o "il momento più avanzato" dessa "cultura civile del primo Settecento". FRIGO, Daniela. Principe, Giudici, Giustizia: Mutamenti Dottrinali e Vicende Istituzionali fra Sei e Settecento. In: COLAO, Floriana; BERLINGER, Luigi (Org.). Illuminismo e Dottrine Penali. Milano: Giuffrè, 1990, pp. 3-38, p. 19.
} 
efetivamente governar seus domínios, superando-se assim a passividade real em face das autonomias estamentais e corporativas do antigo regime e infringindo, quando necessário, os limites tradicionais à ação governativa para dirigir a sociedade à prosperidade material, que era identificada com a ideia de "felicidade pública".

No âmbito dessa abordagem, a intensificação do absolutismo monárquico se justificava em virtude da necessidade de oferecer ao soberano os meios necessários ao efetivo governo da sociedade rumo à prosperidade. Essa orientação assumiu formas diversas, tais como o discurso antimaquiavelista tão bem representado por Frederico II da Prússia em sua obra de juventude, intitulada justamente 0 Anti-Maquiavel ${ }^{9}$. Segundo o então futuro rei prussiano, o príncipe era responsável pela saúde e prosperidade de seus súditos e deveria personificar uma forma de estadismo benevolente que seria o contrário das supostamente astutas maquinações propostas pelo pensador florentino.

Não por coincidência, seria também na Prússia que se desenvolveria a chamada ciência da polícia (Polizeiwissenschaft) que, muito embora colocando mais ênfase sobre o interesse do próprio soberano na conservação e fortalecimento de seus domínios em face de rivais internos e externos, se preocuparia em desenvolver de forma mais detalhada eficientes métodos de administração da burocracia estatal, de disciplinamento social e de estímulo à atividade econômica em chave pós-mercantilista. ${ }^{10}$

$\mathrm{Na}$ contramão dessa configuração política que unia coroa, burguesia e baixa nobreza estavam - além dos estamentos privilegiados, como a alta nobreza - também os membros das castas jurídicas. Em casos mais extremos, altos tribunais foram polos de resistência ao absolutismo monárquico. ${ }^{11}$ Mas, de qualquer forma, por toda parte a prática jurídica baseava-se em fontes não diretamente acessíveis à intervenção e manipulação principescas, tais como o direito romano ou o direito costumeiro.

\footnotetext{
${ }^{9}$ FREDERICO II. O Anti-Maquiavel. Tradução de Ivone C. Benedetti. São Paulo: WMF Martins Fontes, 2014. Sobre o antimaquiavelismo, veja-se MATTEI, Rodolfo De. Dal premachiavellismo all'antimachiavellismo. Firenze: G.C. Sansoni, 1969.

${ }^{10}$ Sobre a evolução do conceito de "polícia" até a época do reformismo absolutista do século XVIII, veja-se SEELAENDER, Airton L. Cerqueira Leite. A "Polícia" e as Funções do Estado: Notas sobre a "Polícia" do Antigo Regime. Revista da Faculdade de Direito. Universidade Federal do Paraná, v. 49, p. 73-87, 2010a. Sobre a Polizeiwissenschaft nas áreas de língua alemã, vejam-se STOLLEIS, Michael. Geschichte des öffentlichen Rechts in Deutschland. Band 1: Reichspublizistik und Policeywissenschaft 1600 bis 1800. München: Beck, 1988; SCHULZE, Reiner. Policey und Gesetzgebungslehre im 18. Jahrhundert. Berlin: Duncker \& Humblot, 1982; SCHIERA, Pierangelo. Il cameralismo e l'assolutismo tedesco: Dall'arte di governo alle scienze dello Stato. Milano: A. Giuffre, 1968.

${ }^{11} \mathrm{O}$ caso mais notório talvez seja o do Parlement de Paris. Sobre os Parlements em geral e, em especial, o Parlement de Paris, veja-se TARELLO, Giovanni. Storia della cultura giuridica moderna: assolutismo e codificazione del diritto. Bologna: Società editrice il Mulino, 1999, p. 57.
} 
MURATORI E OS DEFEITOS DA JURISPRUDÊNCIA: CONSIDERAÇÕES SOBRE OS FUNDAMENTOS TEÓRICOS DAS REFORMAS JURÍDICAS SETECENTISTAS

ALEXANDER DE CASTRO

De tal maneira, enquanto as escolas de pensamento jurídico mais próximas do pensamento político e filosófico contribuíram decisivamente para os programas reformistas do absolutismo monárquico, a teoria jurídica que se decantava da prática forense e notarial tendia, ao contrário, a obstaculizar os interesses centralizadores e regulatórios dos monarcas reformadores. ${ }^{12}$

Portanto, a crítica à scientia iuris do antigo regime, em especial àquela que se desenvolvia por obra dos praxistas e de algumas escolas romanistas, era praticamente um caminho natural a seguir para quem quer que se aventurasse no campo teórico-político próabsolutista. Muratori constituiu um dos exemplos mais eloquentes da crítica à ciência do direito sob o pano de fundo da defesa do ativismo monárquico daqueles "bons príncipes" que se deveriam ocupar da "felicidade pública" de seus domínios. Em uma de suas mais famosas obras, intitulada justamente “Da Felicidade Pública, objeto dos bons príncipes”, Muratori afirma que "consiste o ofício e emprego dos verdadeiros e sábios príncipes em continuamente estudar o bem público, obtendo para o seu povo aquela felicidade que é possível no mundo", coisa com a qual apenas não estariam de acordo "alguns maquiavelistas". ${ }^{13}$

Em Da Felicidade Pública, Muratori segue de perto justamente o modelo dos manuais e tratados de ciência da polícia que já tinham popularizado no espaço de língua alemã. De tal forma, vinha tratado um amplo elenco de matérias como a instrução, a religião, a medicina, a agricultura, o comércio, o provisionamento de gêneros alimentares (annona), o luxo, a ordem pública, os impostos, a moeda, a caça e a pesca, a milícia, a saúde pública e o saneamento, todos assuntos considerados essenciais à gestão interna do Estado. ${ }^{14}$

\footnotetext{
12 Para Tarello, essa tendência conservadora dos práticos do direito é ainda acentuada nos lugares em que "ainda não se havia formado uma burguesia e os juristas práticos estão, por isso, ao serviço da nobreza feudal e não de uma classe nova". Veja-se TARELLO, Giovanni. Storia della cultura giuridica moderna: assolutismo e codificazione del diritto. Bologna: Società editrice il Mulino, 1999, p. 34 [tradução nossa].

${ }^{13}$ MURATORI, Ludovico Antonio. Della pubblica felicità: oggetto de' buoni prìncipi. Roma: Donzelli Editore, 1996, p. 15. O antimaquiavelismo de Muratori aparenta ser também, ao menos em parte, tributário do antimaquiavelismo católico posterior ao Concílio de Trento, que viu renascer o gênero dos "espelhos de príncipe". Nesse sentido, veja-se DARRICAU, Raymond. Le Prince chrétien dans la pensée de Lodovico Antonio Muratori. In: LA FORTUNA DI L. A. MURATORI: Atti del convegno internazionale di studi muratoriani, 1972, Modena. Anais impressos. Firenze, Olschki, 1975, pp. 331-47. Acredita-se, entretanto, que essa vinculação ao antimachiavelismo da contrarreforma não deva ser superestimada. 0 ponto de contato entre eles parece estender-se exclusivamente até os deveres éticos do príncipe, dentre os quais Muratori incluiria a ativa promoção da felicidade dos súditos, o que abriria a porta a contatos com a agenda de outras correntes teóricas pró-absolutistas do século XVIII. Não seria exagerado até mesmo cogitar que, para facilitar sua aceitação em cículos mais conservadores, a explícita vinculação com os antimaquiavelistas da contrarreforma buscada por Muratori tinha a finalidade de transmitir a aparência de uma continuidade com a tradição católica que, de fato, não era assim tão forte.

${ }_{14}$ Para uma apreciação geral do reformismo de Muratori, veja-se VECCHI, Alberto. Nota sul riformismo di Muratori. Rassegna italiana di politica e di cultura. Roma, n. 315, pp. 76-89, fevereiro, 1951. A obra Da
} 
Nesse longo catálogo temático, comparecem também o direito e as leis. Atento ao que ele considerava os inconvenientes causados por uma estrutura jurídica julgada fragmentada e confusa, Muratori viu no soberano a força necessária para dar alguma organização e certeza ao direito. Já em 1726, ele compõe uma exortação endereçada ao Imperador Carlos XI intitulada "Sobre o código carolino ou sobre a formação de um novo código de leis"15, no qual se aspirava a uma intervenção simplificadora do soberano sobre o direito para reduzi-lo a um pequeno número de leis reunidas em um código oficial. Posteriormente, Muratori retomaria a questão na mais profunda e conhecida obra Dos defeitos da Jurisprudência ${ }^{16}$, onde ele se dedicou a elencar de maneira meticulosa os problemas da jurisprudência da tradição justiniana.

\section{OS DEFEITOS DA JURISPRUDÊNCIA E O “MERCADO DO FORO”}

Os defeitos da jurisprudência são subdivididos por Muratori em duas categorias, quais sejam os defeitos intrínsecos à jurisprudência e aqueles externos. Entre os defeitos internos, o primeiro que ele enumera é a obscuridade das leis. Afirma ele que "deveriam estas ser claras, com termos que exprimissem bem a mente do legislador; mas nem aquelas todas que temos no corpo do lus de Justiniano, nem os estatutos das várias cidades, possuem esta qualidade; ao contrário, sujeitam-se a várias interpretações"17. 0 segundo defeito intrínseco da jurisprudência

Felicidade Pública é, de certa forma, também uma síntese do pensamento muratoriano na qual são resumidos os diversos temas de que ele se ocupou ao longo de sua carreira literária. Nesse sentido, vejase SORBELLI, Tommaso. Nel bicentenario della pubblicazione della "Pubblica felicita". Atti e Memorie della R. Deputazione di Storia Patria per le Antiche Provincie Modenesi. Modena, Série VIII, vol. II, pp. 239-255, 1949, p. 254.

15 No original: De codice carolino, sive de novo legum codice instituendo. Veja-se MURATORI, Lodovico Antonio. De Codice Carolino. In: DONATI, Benvenuto. Lodovico Antonio Muratori e la giurisprudenza del suo tempo. Modena: Pubblicazioni della Facoltà di Giurisprudenza presso l'Università degli Studi, 1935, pp. 173-209. Sobre o “códice Carolino", veja-se ainda DONATI, Benvenuto. Storia critica del De Codice Carolino. In: MURATORI, Lodovico Antonio. Scritti giuridici complementari del trattato del 1742 "Dei difetti della giurisprudenza". I. De Codice Carolino II. Pareri legali. Testi inediti con annotazione a cura di Benvenuto Donati. Modena: Società Tipografica Modenese, 1942, pp. 53-75.

${ }^{16}$ MURATORI, Ludovico Antonio. Dei difetti della giurisprudenza. Venezia: Presso Giambattista Pasquali, 1747. Para um balanço geral da obra, vejam-se DONATI, Benvenuto. La critica del Muratori alla giurisprudenza. Modena: Pubblicazioni della Facoltà di Giurisprudenza presso l'Università degli Studi, 1934; PATTARO, Enrico. I difetti della giurisprudenza di Muratori. Rivista internazionale di filosofia del diritto. Milano, série IV, n. 50, pp. 88-144, 1973; SORBELLI, Tommaso. Nel bicentenario della pubblicazione dei “Difetti della Giurisprudenza” di L. A. Muratori. Studi e documenti. Reggio Emilia, n. XXI, vol. II, pp. 258- 272, 1943.

17 No original: "Dovrebbero queste esser chiare, con termini ben esprimenti la mente del legislatore; ma nè pur tutte quelle, che abbiamo nel corpo del Gius di Giustiniano, o ne gli statuti di varie città, portano in sè questo pregio; e però si rendono suggette a varie interpretazioni”. MURATORI, Ludovico Antonio. Dei difetti della giurisprudenza. Venezia: Presso Giambattista Pasquali, 1747, p. 11 [tradução livre]. 
reside no fato de que as leis "não regulam, nem podem regular todos os casos, os quais podem ser muitíssimos, para não dizer infinitos"18.

De tal forma, mesmo quando uma lei é “claríssima e precisa”"19 ainda assim não será possível prever várias circunstâncias com relação às quais algum aspecto relevante da questão possa emergir. E eis que daí surgem tantas “exceções e limitações”, baseadas na ideia de que "os legisladores em certos, e estes muitíssimos, casos não tenham podido ou querido vetar ou ainda comandar alguma coisa"20. O terceiro defeito diz respeito à interpretação das próprias interações humanas às quais se aplicam as leis e "consiste no descobrir e interpretar a vontade e intenção dos homens procurando extrai-la dos fatos ou ainda das palavras dos mesmos mortais" 21 , tarefa esta que é "sumamente difícil” e "que abre o campo para uma interminável confusão de litígios". 22

O quarto defeito intrínseco da jurisprudência vem da inexistência de regras que regulem a aplicação das normas gerais que as leis contêm sobre o justo e o injusto aos casos particulares. Assim, no fim das contas "tudo depende da prudência, ou no mais das vezes da opinião, que é diversa segundo a diversidade dos cérebros." 23 Para esse conjunto de defeitos intrínsecos da jurisprudência e da judicatura, Muratori afirma peremptória e resignadamente que não há remédios. No fim, também a jurisprudência - assim como a moral e a medicina - tem seus limites imanentes. $^{24}$

A outra categoria de defeitos da jurisprudência, os defeitos externos, constrói-se, de maneira progressiva, sobre a base daqueles intrínsecos. Assim, com base nas dificuldades e

\footnotetext{
${ }^{18}$ No original: "Il secondo interno difetto nasce dall'essere tali le leggi, che non provveggono, nè possono provvedere a tutti i casi, i quali possono essere moltissimi, per non dire infiniti." MURATORI, Ludovico Antonio. Dei difetti della giurisprudenza. Venezia: Presso Giambattista Pasquali, 1747, p. 11 [tradução livre].

${ }_{19}$ MURATORI, Ludovico Antonio. Dei difetti della giurisprudenza. Venezia: Presso Giambattista Pasquali, 1747 , p. 12 [tradução livre].

${ }^{20}$ MURATORI, Ludovico Antonio. Dei difetti della giurisprudenza. Venezia: Presso Giambattista Pasquali, 1747, pp. 11-2 [tradução livre].

${ }^{21}$ No original: "Il terzo interno difetto [...] consiste nello scoprire, ed interpretare la volontà ed intenzione de gli uomini, con ricavarla da i fatti, o pur dalle parole de gli stessi mortali." MURATORI, Ludovico Antonio. Dei difetti della giurisprudenza. Venezia: Presso Giambattista Pasquali, 1747, p. 12 [tradução livre].

${ }_{22}$ MURATORI, Ludovico Antonio. Dei difetti della giurisprudenza. Venezia: Presso Giambattista Pasquali, 1747, p. 12 [tradução livre].

${ }^{23}$ No original: "E poi perchè sovente si tratta della volontà ed intenzione altrui, ad interpretare la quale non abbiam regola alcuna sicura, e tutto dipende dalla prudenza, e per lo più dall'opinione, che è varia secondo la varietà de' cervelli." MURATORI, Ludovico Antonio. Dei difetti della giurisprudenza. Venezia: Presso Giambattista Pasquali, 1747, p. 13 [tradução livre].

${ }^{24}$ MURATORI, Ludovico Antonio. Dei difetti della giurisprudenza. Venezia: Presso Giambattista Pasquali, 1747, pp. 11, 16 [tradução livre].
} 
dúvidas inerentes à obscuridade das leis, sua incapacidade de cobrir todos os casos possíveis e sua incerta aplicação às especificidades da convivência humana, surge a necessidade de se interpretar as leis. 0 primeiro problema daí derivado é que o número de intérpretes da lei se multiplica de forma indeterminada e termina-se por havê-los em demasia.

De tal forma, da infinidade de volumes de obras jurídicas, esperar-se-ia que a compreensão das leis seria tornada fácil. "Exatamente o contrário", arremata Muratori. E prossegue: “A outra coisa não serviu, nem serve este dilúvio de obras legais, se se pensa bem, do que a tornar a jurisprudência mais difícil, emaranhada e espinhosa, e mais incertos e duvidosos os juízos de quem deve administrar a justiça." ${ }^{25}$ A causa não é outra que a completa disparidade das interpretações, compostas de "uma infinidade de sentenças e conclusões todas em guerra entre si, isto é, contrárias ou contraditórias."26

Assim, se, para a solução de uma controvérsia, dez autores estabelecem uma máxima, basta continuar a procurar "e encontrareis outros vinte ou trinta que divulgam e consolidam com razões diversas um parecer diferente." 27 O sentido da lei, por via dos muitos intérpretes que se multiplicam, ganha enorme pluralidade de orientações. E muitas, alcançando enorme difusão, tornam-se opiniões comuns ainda que díspares e contraditórias entre si. Essas seriam, portanto, as bases nada nobres do instituto da communis opinio doctorum. ${ }^{28}$

A mais grave consequência desse fato é a própria dissolução da força normativa e da autoridade da lei. As interpretações das leis feitas pelos jurisconsultos que se põem a explicá-las acabam se substituindo a essas mesmas leis. Assim, afirma Muratori que "os doutores já há muito tempo transformaram-se em legisladores, e o mundo de hoje presta mais atenção às suas

\footnotetext{
${ }^{25}$ No original: "Tutto l'opposto. Ad altro non ha servito, nè serve questo diluvio d'opere legali, se vi si farà ben mente, che a rendere la giurisprudenza più difficile, imbrogliata e spinosa, e più incerti e dubbiosi i giudizj di chi dee amministrar la gustizia." MURATORI, Ludovico Antonio. Dei difetti della giurisprudenza. Venezia: Presso Giambattista Pasquali, 1747, p. 20 [tradução livre].

${ }^{26}$ No original: "Volgete e rivolgete questi libri: troverete un'infinità di sentenze e conclusioni tutte in guerra fra loro, cioè contrarie o contraddittorie." MURATORI, Ludovico Antonio. Dei difetti della giurisprudenza. Venezia: Presso Giambattista Pasquali, 1747, p. 20 [tradução livre].

${ }_{27}$ No original: "Allorchè avrete osservato in dieci autori, come s'ha a stabilire una massima, a decidere una controversia: passate innanzi, e venti o trenta altri ne incontrerete, che spacciano e assodano con ragioni diverse un differente parere." MURATORI, Ludovico Antonio. Dei difetti della giurisprudenza. Venezia: Presso Giambattista Pasquali, 1747, p. 20 [tradução livre].

${ }^{28}$ Sobre a communis opinio doctorum veja-se COING, Helmut. Europäisches Privatrecht. vol. I: Älteres gemeines Recht. München: C. H. Beck'sche Verlagsbuchhandlung, 1985, pp. 124-6; SBRICCOLI, 1969, pp. 384-92; SCHRÖDER, Jan. Recht als Wissenschaft: Geschichte der juristischen Methodenlehre in der Neuzeit (1500-1933). 2. Ed. München: Beck, 2012, pp. 47-50, 128-32.
} 
opiniões que às já quase rançosas antigas leis”. ${ }^{29}$ A opinião dos doutores transforma-se em lei a tal ponto "que às vezes se encontram laureados defensores de causas que nunca leram o corpo das leis de Justiniano" 30 .

Para consolidação sob a forma de lei válida no foro dessa pluralidade de distintas opiniões doutorais concorrem os advogados, que obviamente fazem uso indiscriminado de qualquer opinião que melhor sirva aos interesses de seus clientes em cada causa, e até mesmo os juízes, que podem "decidir as causas em favor de quem mais thes agrada" visto que agora "qualquer sentença que eles queiram proferir, a encontram assistida pela autoridade de muitos jurisconsultos, e em livros impressos e esta [a sentença] declarada por eles com o título majestoso de comum". ${ }^{31}$

De tal forma, por via dos vários interesses contrapostos, várias opiniões são inseridas, por advogados ou juízes, "em suas consultas ou em suas decisões”, fazendo crescer "o catálogo dos aderentes" a cada uma delas: e "eis formada, eis canonizada a lei." 32 Assim, a jurisprudência doutoral não apenas usurpa a faculdade de legislar, mas ainda o faz de forma caótica e desorganizada.

Considerados em seus efeitos conjuntos, os defeitos externos da jurisprudência e da judicatura são relacionados com a prática jurídica. Toda a crítica de Muratori à jurisprudência diz respeito, portanto, ao que ele chama de "jurisprudência prática”33. São os advogados que, no interesse de seus clientes, fazem uso de "sutilezas, sofismas e da arte de embaraçar os fatos para comprovar as próprias razões e enfraquecer as do adversário, fazendo aparecer nuvens e

\footnotetext{
${ }^{29}$ No original: "Anche i dottori da gran tempo son divenuti legislatori, e il mondo d'oggidì più bada alle loro opinioni, che alle oramai quasi rancide antiche leggi”. MURATORI, Ludovico Antonio. Dei difetti della giurisprudenza. Venezia: Presso Giambattista Pasquali, 1747, p. 23 [tradução livre].

30 No original: "Tal piede anzi ha preso questa dottorale giurisprudenza, che si troveran talvolta de $i$ laureati difensori di cause, che non hanno mai letto il corpo delle leggi di Giustiniano". MURATORI, Ludovico Antonio. Dei difetti della giurisprudenza. Venezia: Presso Giambattista Pasquali, 1747, p. 22 [tradução livre].

${ }^{31}$ No original: "Il peggio è che con ciò s'è aperto un bel campo a i giudici, qualor ne venga loro talento, e l'amicizia, o l'odio, o altre passioni vogliano essere esaudite, di decidere le cause in favore di chi è più loro in grado. Perciocchè qualunque sentenza, ch'essi vogliano profferire, la truovano assistita dall'autorità di molti giurisconsulti, e in libri stampati, e questa dichiarata da essi con titolo maestoso comune." MURATORI, Ludovico Antonio. Dei difetti della giurisprudenza. Venezia: Presso Giambattista Pasquali, 1747, pp. 21-2 [tradução livre].

32 No original: "Si pianta da un accreditato legista qualche conclusione, forse perchè ne ha bisogno in quel tempo. Quei, che vengono dopo, la prendono come tant'oro, e trovandola approposito per qualche lor lite, l'infilzano ne' lor consulti, o nelle lor decisioni: e così cresce il catalogo de gli aderenti alla medesima. Ecco formata, ecco canonizzata la legge." MURATORI, Ludovico Antonio. Dei difetti della giurisprudenza. Venezia: Presso Giambattista Pasquali, 1747, pp. 23-4 [tradução livre].

33 MURATORI, Ludovico Antonio. Dei difetti della giurisprudenza. Venezia: Presso Giambattista Pasquali, 1747, p. 3 [tradução livre].
} 
neblina onde é sereno"34.

A eles seguem-se os juízes que, ao invés de decidir com base em um "juízo científico" que seja "capaz de bem distinguir o que é razão ou sofisma, supérfluo ou útil para fundar um reto juízo"35, preferem - por não saberem raciocinar - "valer-se da autoridade dos doutores e dos tribunais que já decidiram sobre aquelas controvérsias" pensando que "quanto mais longa é a fila dos autores alegados, tanto mais parecem eles ter encontrado o seguro fundamento de decidir." 36 Procedendo desse modo, eles - juízes e advogados - não apenas consolidam a pluralidade caótica de interpretações, mas mesmo a estimulam fortemente na medida em que criam para ela uma grande demanda.

Assim, a prática acabava por contaminar a teoria, pois qualquer opinião, por mais disparatada que fosse, encontraria ecos na atividade forense desde que baseada em hábeis sofismas. A jurisprudência era corrompida em uma disciplina praxística, reduzindo-se a "servir ao mercado do foro". ${ }^{37}$ Ao invés de uma ciência pura e especulativa, dedicada a investigar a natureza do justo e do injusto para, se não corrigir, ao menos compensar os defeitos intrínsecos da jurisprudência e atenuar-lhes os efeitos deletérios, a ciência das leis transforma-se em uma disciplina sofística. ${ }^{38}$

A contraposição que Muratori faz entre a teoria pura e especulativa e aquela orientada pragmaticamente para o “mercado do foro" historicamente diz respeito à dissociação entre o cultivo humanista do direito romano e aquela praxística jurídica que se desenvolve em

${ }^{34}$ No original: "nulla poi lascerà indietro non solo di buone ragioni, ma anche di sottigliezze, di sofismi, e d'arte per imbrogliare $i$ fatti, per avvalorar le proprie ragioni, e per indebolir quelle dell'avversario, facendo comparir nuvole e nebbie, dove è sereno". MURATORI, Ludovico Antonio. Dei difetti della giurisprudenza. Venezia: Presso Giambattista Pasquali, 1747, p. 56 [tradução livre].

35 MURATORI, Ludovico Antonio. Dei difetti della giurisprudenza. Venezia: Presso Giambattista Pasquali, 1747, p. 52 [tradução livre].

${ }^{36}$ No original: "L'ordinario contegno di questi tali, che raziocinar non sanno, suol essere di far gran capitale dell'autorità de i dottori, e de i tribunali, che han deciso su quelle controversie. Quanto più lunga è la fila degli autori allegati, tanto più si figurano essi d'aver trovato il sicuro fondamento di decidere." MURATORI, Ludovico Antonio. Dei difetti della giurisprudenza. Venezia: Presso Giambattista Pasquali, 1747, pp. 52-3 [tradução livre].

${ }^{37}$ As acusações sobre servilismo da jurisprudência com relação ao mercado do foro e sua decadência enquanto estudo erudito encontram-se já em uma das primeiríssimas análises de Muratori sobre a ciência do direito, contidas em suas "reflexões sobre o bom gosto". No original: "Dello studio delle Leggi io non terrò punto ragionamento, perché ormai questo non si suol contare fra gli studi Eruditi, da che in Italia solamente si fa servire al mercato del Foro, e sarebbe ed è non già disperata impresa, ma certo assai malagevole voler introdurre riforma e buon Gusto medesimo." MURATORI, Ludovico Antonio. Delle riflessioni sopra il buon gusto. 2. Parte. Venezia: Nicolò Pezzana, 1717, p. 252.

38 Sobre o juízo de Muratori com relação à ciência jurídica do antigo regime, vejam-se DONATI, Benvenuto. Lodovico Antonio Muratori e la giurisprudenza del suo tempo. Modena: Pubblicazioni della Facoltà di Giurisprudenza presso l'Università degli Studi, 1931; ROBERTI, Melchiorre. Lodovico Antonio Muratori e il tramonto del diritto comune. Rivista storica di diritto italiano. Bologna, n. 9, pp. 12-36, 1936, pp. 12-36. 
praticamente toda a Europa durante a primeira modernidade. Entre fins do século XV e primórdios do século $\mathrm{XVI}$, desenvolve-se o estudo erudito dos textos jurídicos romanos (o chamado mos gallicus) que, utilizando-se dos métodos de análise filológica e da crítica histórica típicas do humanismo renascentista, se esforçava por superar as inocências das escolas romanistas medievais (o chamado mos italicus) no tratamento dos textos do Corpus luris Civilis.

Almejava-se, assim, reconstruir o direito romano em sua substância ao mesmo tempo pura e historicamente original, superando até mesmo os tribonianismos, isto é, as interpolações feitas por Triboniano - ministro de Justiniano (quaestor sacri palatii) responsável pelo Corpus luris Civilis - aos textos clássicos dos juristas romanos. ${ }^{39} \mathrm{O}$ humanismo jurídico alcançou grande difusão nos meios universitários franceses, belgas e holandeses e reverberou com força mesmo na Itália. Entretanto, seu interesse pela reconstrução do direito romano e sua consequente inadequação às necessidades práticas da vida civil e comercial impediu que suas elaborações teóricas tivessem grandes repercussões forenses ou notariais, mesmo lá onde sua hegemonia universitária foi inquestionável.

De tal forma, por quase todo o território europeu, desenvolveu-se uma literatura orientada à prática e dedicada a comentar seja o direito romano, sejam as leis estatutárias à luz das decisões e procedimentos das cortes e tribunais, cultivando ainda grande deferência por Bártolo, Acúrsio e demais doutores medievais. Ao longo do tempo, por toda a parte essa literatura, foi-se insinuando para dentro do ensino universitário, conseguindo avançar extensamente, sobretudo - por óbvio - onde o humanismo jurídico não tinha alcançado grande difusão.

O exemplo mais conhecido desse processo foram as primeiras gerações de juristas do usus modernus pandectarum dos territórios de língua alemã (Benedikt Carpzov, Georg Adam Struve, David Mevius entre outros $)^{40}$, mas também Giulio Claro e Prospero Farinacci ${ }^{41}$ na Itália ou Manuel

\footnotetext{
${ }^{39}$ Para uma análise geral das bases metodológicas do pensamento jurídico de Muratori, vejam-se TARDINI, Luigi Vincenzo. I fondamenti della concezione giuridica di L. A. Muratori: Studi sul trattato «La Filosofia Morale». Modena: Società tipografica modenese, 1937; PATTARO, Enrico. II pensiero giuridico di L. A. Muratori tra metodologia e politica. Milano: Giuffrè, 1974.

40 Para uma visão geral sobre o usus modernus pandectarum, veja-se WIEACKER, Franz. Privatrechtsgeschichte der Neuzeit: unter besonderer Berücksichtigung der deutschen Entwicklung. Göttingen: Vandenhoeck \& Ruprecht, 1967, pp. 204-48. Para uma análise mais atual de vários aspectos do usus modernus, vejam-se WILLOWEIT, Dietmar. Der Usus modernus oder die geschichtliche Begründung des Rechts. Zur rechtstheoretischen Bedeutung des Methodenwandels im späten 17. Jahrhundert. In: WILLOWEIT, Dietmar (Org.). Die Begründung des Rechts als historisches Problem. München: Oldenbourg Verlag, 2000, pp. 229-46; VOPPEL, Reinhard. Der Einfluß des Naturrechts auf den usus modernus: Eine Untersuchung anhand der Literatur zum geltenden Recht im 17. und 18. Jahrhundert. Köln: Heymann, 1996; RANIERI, Filippo. Entscheidungsfindung und Technik der Urteilsredaktion in der Tradition des deutschen Usus Modernus: das Beispiel der Aktenrelationen am Reichskammergericht. In: WIJFFELS, Alain
} 
Gonçalves da Sylva e Manuel Lopes Ferreira em Portugal.

\section{A CORREÇÃO DOS DEFEITOS DA JURISPRUDÊNCIA E O ABSOLUTISMO}

Ao contrário dos intrínsecos, os defeitos externos poderiam, em tese, ser corrigidos. Mas é seguro dizer que, em princípios do século XVIII, a Muratori pareceria inocência esperar que essa correção partisse de um movimento interno da própria ciência jurídica, muito embora isoladamente algumas correntes do pensamento jurídico pudessem apontar nessa direção. De tal forma, ele avançava a hipótese de uma intervenção do príncipe sobre o direito. Entretanto, reformador moderado que era, Muratori não chamava o príncipe a proscrever o direito justiniano, mas somente a corrigir seus defeitos, simplificando-o e sistematizando-o.

De fato, Muratori confessava grande respeito pelo direito romano, afirmando que "ao corpo de leis de Justiniano, torno a dizer que me uno também eu com a república legal em protestar-lhe dignas de grande veneração", ainda que ponderasse contra a comum crença no caráter de ratio scripta atribuído ao direito do Corpus luris Civilis lembrando "não ser aquele um livro caído do céu, nem o mais perfeito modelo que se possa jamais imaginar da jurisprudência humana", ${ }^{42}$ eis que nelas encontrar-se-iam contradições, obscuridades e muitas superfluidades.

Assim, ele propunha como solução “que os príncipes fizessem compor um exatíssimo e claro extrato e compêndio metódico de todas as leis de Justiniano, convenientes ao uso de

(Org.). Case Law in the Making: The Techniques and Methods of Judicial Records and Law Reports. Vol. 1. Berlin: Duncker und Humblot, 1997, pp. 277-297; Veja-se também LUIG, Klaus. Samuel Stryk (1640-1710) und der usus modernus pandectarum. In: LUIG, Klaus. Römisches Recht, Naturrecht, nationales Recht. Goldbach: Keip, 1998, pp. 91-107.

${ }^{41}$ Sobre Claro e Farinacci no contexto da ciência jurídico-penal entre os séculos XVI e XVII, veja-se MARONGIU, Antonio. La scienza del diritto penale nei secc.XVI-XVIII. In: La formazione storica del diritto moderno in Europa. Atti del III congresso internazionale della Società italiana di storia del diritto. Tomo I. Firenze: Leo S. Olschki Editore, 1977, pp. 409-429. Sobre Claro, veja-se a clássica obra de MOELLER, Ernst von. Julius Clarus aus Alessandria, der Kriminalist des 16. Jahrhunderts, der Rat Philipps II. 1525-1575. Aalen: Scientia Verlag, 1977. Sobre Farinacci, veja-se RE, Niccolò Del. Prospero Farinacci, Giureconsulto Romano (1544-1618). Roma: Fondazione Marco Besso, 1999.

42 No original: "E primieramente quanto al corpo delle leggi di Giustiniano, torno a dire, che m'unisco anch'io colla repubblica legale in protestarle degne di gran venerazione, e in credere, che contengano innumerabili e maravigliosi lumi per ben giudicare del tuo e del mio. Contuttociò chieggo licenza di ripetere, non esser già quello un libro caduto dal cielo, nè il più perfetto modello, che si possa mai immaginare dell'umana giurisprudenza." MURATORI, Ludovico Antonio. Dei difetti della giurisprudenza. Venezia: Presso Giambattista Pasquali, 1747, p. 66. 
nossos tempos, eliminando as supérfluas, as reprovadas e as contraditórias" ${ }^{43}$. A reforma do sistema jurídico em Muratori deveria ser, portanto, formal e não conteudística. ${ }^{44}$ Uma reforma na arrumação formal do material jurídico deveria ser já suficiente para enfraquecer um dos principais sustentáculos do poder do estamento dos juristas, isto é, o seu monopólio sobre a determinação do direito aplicável, baseado na possibilidade que se tem de se aproveitar do caos das leis para "fazê-las dizer aquilo que querem ora em uma, ora em outra maneira" 45.

Toda a reflexão de Muratori sobre os "defeitos da jurisprudência" e os modos de corrigilos é parte integrante de seu projeto antimaquiavelista de promoção da "felicidade pública" a partir da modernização institucional e da intervenção do soberano no metabolismo social em detrimento das autonomias corporativas. O reformismo de Muratori, quando analisado de maneira global, não é - como quer Tarello - apenas intrajurídico ou meramente supraestrutural. $^{46}$

Ao contrário, quando se considera a sua obra de maturidade à luz dos temas dominantes da literatura política da época e, sobretudo, com atenção aos embates políticos e à evolução institucional deles resultante no norte da Itália e em muitos dos territórios habsburgos, fica claro que Muratori era bastante consciente dos desafios econômico-sociais de sua região na primeira metade do século XVIII e compreendia com profundidade o papel que as instituições judiciais e a própria ciência jurídica exerciam dentro daquela realidade. ${ }^{47}$

Assim, utilizando-se dos instrumentos teóricos que estavam à disposição em sua época -

\footnotetext{
${ }^{43}$ No original: “E certo si potrebbe proporre alla bilancia de' saggi questo problema: cioè se tornasse più il conto alla nostra giurisprudenza, che i principi facessero comporre un esattissimo e chiaro estratto e compendio metodico di tutte le leggi di Giustiniano, convenevoli all'uso de' nostri tempi, risecando le superflue, le riprovate, e le contrarie". MURATORI, Ludovico Antonio. Dei difetti della giurisprudenza. Venezia: Presso Giambattista Pasquali, 1747, p. 67.

${ }^{44}$ Sobre as soluções propostas por Muratori para os defeitos da jurisprudência, vejam-se PATTARO, Enrico. Il buon legislatore e il buon interprete nella prospettiva del reformismo metodologico di L. A. Muratori. In: ZUCCHINI, Giampaolo. L'Educazione Giuridica. V. Modelli di legislatore e scienza della legislazione, Tomo I: Filosofia e scienza della legislazione. Napoli: Edizioni scientifiche Italiane, 1988, pp. 157-178; MOR, Carlo Guido. L. A. Muratori fra interpreti e codificazione. Modena: Società Tipografica Modenese, 1942.

${ }^{45}$ MURATORI, Ludovico Antonio. Dei difetti della giurisprudenza. Venezia: Presso Giambattista Pasquali, 1747, p. 66.

46 Segundo Giovanni Tarello, o reformismo de Muratori, enquanto "mais nítida expressão da ideologia da codificação típica da primeira metade do século XVIII", não estava inserido em um projeto de maior de renovamento social. Ao contrário, exprimia apenas o desejo por uma "codificação qualquer" não necessariamente "funcional a uma reforma ou renovamente político geral, mas limitada a uma visão de mero renovamento jurídico". Tratar-se-ia, portanto, de "uma tentativa que se desenvolve toda em um nível, por assim dizer, supraestrutural” na qual não haveria qualquer "'abertura' aos problemas economico-sociais". TARELLO, Giovanni. Storia della cultura giuridica moderna: assolutismo e codificazione del diritto. Bologna: Società editrice il Mulino, 1999, pp. 207-8.

${ }^{47}$ Nesse sentido também VECCHI, Alberto. Nota sul riformismo di Muratori. Rassegna italiana di politica e di cultura. Roma, n. 315, pp. 76-89, fevereiro, 1951.
} 
isto é o Cameralismo e o discurso antimaquiavelista da felicidade pública - ele propôs o seu plano de ação: a intervenção diretiva do soberano, que organiza a legislação, doma a ciência jurídica e disciplina as forças sociais em favor do bem geral, da prosperidade dos súditos e do fortalecimento do Estado. ${ }^{48}$

A fórmula de Muratori para dar solução aos problemas da época era, portanto, muito simples: era necessário um príncipe que fosse um efetivo governante da sociedade, ainda que para sê-lo ele devesse "despoticamente" infringir os direitos tradicionais, violar a esfera de autonomia dos corpos sociais e por de lado os poderes intermediários que se colocavam entre o soberano e os súditos. Essa desvalorização da sociedade tradicional-corporativa de certa forma refletia também uma importante mudança nos critérios de legitimação do poder em geral, da ação governativa e da criação de direito: significava que a tradição já não podia mais servir como ponto de referência e fundamento de legitimidade único do poder e do direito. Apontavase para a tendência a avaliar a ação governativa a partir de seus resultados práticos.

O critério básico de aferição da legitimidade do poder político e jurisdicional deveria ser agora a felicidade pública, que não significava muito mais que o progresso material da comunidade política e o consequente fortalecimento institucional da coroa. Para essa linha de pensamento, que ganhará expressões cada vez mais radicais ao longo do século XVIII, tratava-se de se verificar a adequação das medidas legislativas ou político-administrativas à consecução daquelas finalidades das quais o príncipe era agora encarregado.

No discurso político, emergia daí uma espécie de racionalismo instrumental guiado por critérios utilitaristas (felicidade pública, bem-estar geral, felicidade do maior número), de enorme afinidade com os programas de governo autocráticos do tardo-absolutismo setecentista, cujas maiores expressões aparecerão mais tarde sob a forma filosoficamente refinada de um Jeremy Bentham. Muratori certamente não foi tão longe, mas com seu "utilitarismo" de índole, digamos, político-econômico, dedicado a ensinar aos monarcas cada vez centralizadores a como mudar para melhor a sociedade, ele colocava em debate já na metade do século XVIII os elementos básicos daquilo que seria sintetizado na ideia de absolutismo esclarecido. ${ }^{49}$

\footnotetext{
${ }^{48}$ Analisando a obra de Muratori no processo de construção da imagem do rei-legislador, que é ao mesmo tempo também um "rei-administrador", Daniela Frigo ressalta o compromisso de suas ideias com as necessidades sociais de que o rei se fazia encarregado enquanto intérprete da "felicidade pública". Vejase FRIGO, Daniela. Principe, Giudici, Giustizia: Mutamenti Dottrinali e Vicende Istituzionali fra Sei e Settecento. In: COLAO, Floriana; BERLINGER, Luigi (Org.). Illuminismo e Dottrine Penali. Milano: Giuffrè, 1990, pp. 3-38, p. 19-20.

${ }^{49}$ Nesse sentido, também FRIGO, Daniela. Principe, Giudici, Giustizia: Mutamenti Dottrinali e Vicende Istituzionali fra Sei e Settecento. In: COLAO, Floriana; BERLINGER, Luigi (Org.). Illuminismo e Dottrine Penali. Milano: Giuffrè, 1990, pp. 3-38, p. 18. Sobre esse assunto, veja-se também RICUPERATI, Giuseppe.
} 
MURATORI E OS DEFEITOS DA JURISPRUDÊNCIA: CONSIDERAÇÕES SOBRE OS FUNDAMENTOS TEÓRICOS DAS REFORMAS JURÍDICAS SETECENTISTAS

ALEXANDER DE CASTRO

O absolutismo de Muratori, no entanto, seria ainda mais propriamente um absolutismo paternalístico do que um absolutismo esclarecido. Essa diferença conceitual é, porém, mais nítida em sua expressão teórica e filosófica do que na realidade histórica. ${ }^{50}$ Entre Muratori e os filósofos iluministas que idealizariam a figura do rei artífice do progresso social, amigo das artes e das ciências e que governa com a razão, há certamente muitas diferenças.

Os exemplos históricos que materializaram ambas as abordagens, entretanto, são mais ou menos os mesmos: Maria Teresa, Catarina II, Frederico II da Prússia, e eram os soberanos aos quais se destinava o apoio ideológico dos discursos da felicidade pública e do bem-estar geral. Eram esses também as principais inspirações de Voltaire, Beccaria, Kant, etc., em suas respectivas defesas de uma autocracia amiga da razão. Que o próprio Muratori tenha servido de inspiração para os filósofos iluministas, aos menos os iluministas italianos, é algo bastante provável. ${ }^{51}$ A continuidade teórica e argumentativa entre eles, ao menos em alguns dos aspectos centrais dessa questão, é bastante óbvia. ${ }^{52}$

A imagem muratoriana de um soberano enquanto efetivo governante responsável pela felicidade geral, ao contrário de passivo conservador da ordem, possui grande afinidade com o ideário iluminista. A desvalorização da tradição enquanto força de legitimação das instituições e do poder, apenas implícita em Muratori, era bandeira de combate da filosofia das luzes, que nela

Il pensiero politico degli illuministi. In: FIRPO, Luigi (Org.). Storia delle idee politiche, economiche e sociali. Torino: Utet, 1975, pp. 245-402, pp. 267-9.

50 Max Weber, por exemplo, chegava mesmo a dizer que "a dominação política substancialmente patriarcal adotou o tipo do Estado de bem-estar". E o "despotismo esclarecido" era visto por ele justamente como a fase aguda da dominação patrimonial patriarcal. Note-se, também, que por "Estado de bem-estar" não se entende a assunção de obrigações prestacionais no âmbito de direitos sociais como no moderno "Estado de bem-estar social" do pós-guerra. Veja-se WEBER, Max. Economia e Sociedade. Vol. 2. Tradução de Regis Barbosa e Karen Elsabe Barbosa. Brasília: Editora Universidade de Brasília; São Paulo: Imprensa Oficial do Estado de São Paulo, 1999. Um balanço, com eventual referência à obra de Muratori, das transformações institucionais e político-teóricas entre os séculos XVII e XVIII em direção a um patriarcalismo principesco centralizador e direcionado ao "bem-estar" econômico em FRIGO, Daniela. Principe, Giudici, Giustizia: Mutamenti Dottrinali e Vicende Istituzionali fra Sei e Settecento. In: COLAO, Floriana; BERLINGER, Luigi (Org.). Illuminismo e Dottrine Penali. Milano: Giuffrè, 1990, pp. 3-38. Sobre as raízes mais remotas dessa tendência, vejam-se da mesma autora FRIGO, Daniela. II padre di famiglia: governo della casa e governo civile nella tradizione dell' "econômica" tra cinque e seicento. Roma: Bulzoni Editore, 1985 e FRIGO, Daniela. Disciplina rei familiariae: a economia como modelo administrativo de Ancien Régime. Penélope: revista de história e ciências sociais. Lisboa, n. 6, pp. 47-62, 1991.

${ }^{51}$ Apontando as semelhanças entre Muratori e Beccaria, Vecchi afirma ser provável que o último tenha conscientemente partido das ideias muratorianas. Veja-se VECCHI, Alberto. Nota sul riformismo di Muratori. Rassegna italiana di politica e di cultura. Roma, n. 315, pp. 76-89, fevereiro, 1951, p. 81.

52 Vejam-se VECCHI, Alberto. Nota sul riformismo di Muratori. Rassegna italiana di politica e di cultura. Roma, n. 315, pp. 76-89, fevereiro, 1951; RICUPERATI, Giuseppe. Il pensiero politico degli illuministi. In: FIRPO, Luigi (Org.). Storia delle idee politiche, economiche e sociali. Torino: Utet, 1975, pp. 245-402, p. 267; VENTURI, Franco. Settecento riformatore. Volume I: Da Muratori a Beccaria (1730-1764). Torino: Einaudi, 1987. 
não via mais que um acúmulo de erros e preconceitos representativos de uma época de ignorância.

Além disso, a imagem iluminista do gênero humano racional capaz de progresso e a imagem muratoriana do ativo rei-legislador que corrige e aperfeiçoa a sociedade são profundamente convergentes. Que esse gênero humano seja personificado em um único indivíduo autocrático e autoritário, despótico até mesmo, é algo compreensível em tempos de como pensavam os iluministas - tão disseminada ignorância e em que os "inimigos da razão" eram tão poderosos.

\section{O ILUMINISMO: RADICALIZAÇÃO TEÓRICA DO REFORMISMO JURÍDICO}

Do discurso paternalista da felicidade pública passava-se, assim, facilmente à doutrina do absolutismo esclarecido. 0 que muda de uma época a outra são os instrumentos teóricos mais sofisticados e a radicalidade das propostas de mudança. Na Lombardia, onde viveu Muratori por alguns anos antes de retornar a Módena, menos de vinte anos separam a publicação de sua $D a$ Felicidade Pública e a ascensão do grupo dos filósofos da Accademia dei Pugni, a grande geração de iluministas milaneses cujo principal nome foi Cesare Beccaria. ${ }^{53}$

Agora, sob a influência dos philosophes économistes da fisiocracia e dos materialistas franceses (Helvétius, sobretudo), o tema da felicidade pública reaparece, não apenas enquanto prosperidade material socioeconômica pura e simples, mas sob a fórmula filosoficamente mais elaborada e ampla de satisfação sensorial - que engloba a prosperidade material sem se limitar a ela - expressa pelo lema "a máxima felicidade dividida entre o maior número" ${ }^{4}$. Passava-se,

\footnotetext{
${ }^{53}$ Sobre a Accademia dei Pugni e seu periódico "Il Caffè", veja-se CAPRA, Carlo. Il gruppo del "Caffè" e le riforme. In: FERRONE, Vincenzo; FRANCIONI, Gianni (Org.). Cesare Beccaria: La pratica dei lumi. Atti del Convegno. Firenze: Leo S. Olschki Editore, 2000, pp. 63-78. Sobre as relações de Beccaria com o absolutismo austríaco e o reflexo delas em suas ideias jurídico-penais, veja-se CASTRO, Alexander de; DAL RI JÚNIOR, Arno. Iluminismo e absolutismo no modelo jurídico-penal de Cesare Beccaria. Sequiência: estudos jurídicos e políticos. Florianópolis, n. 57, pp. 261-284, dez. 2008; CASTRO, Alexander de. Beccaria e o direito penal do absolutismo esclarecido: $O$ reformismo habsbúrgico e o lluminismo na Lombardia austríaca. In: DE CASTRO, A.; DAL RI JÚNIOR, A.; SONTAG, R.; DE PAULO, A. Iluminismo e Direito Penal. Florianópolis: Fundação Boiteux, 2009, pp. 13-66. Sobre as ideias jurídico-penais de Beccaria, veja-se também SBRICCOLI, Mario. Beccaria ou l'avènement de l'ordre: le philosophie, les juristes et l'émergence de la question pénale. In: PORRET, Michel. Cesare Beccaria et la culture juridique des lumières: estudes historiques éditée et présentées par Michel Porret. Genève: Librairie Droz S.A., 1997, pp. 178-187. Sobre o contexto das reformas da coroa austríaca na Lombardia, veja-se CAPRA, Carlo. Lo sviluppo delle riforme asburgiche nello Stato di Milano. In: SCHIERA, Pierangelo. La dinâmica statale austríaca nel XVIII e XIX secolo. Bologna: Società editrice il Mulino, 1981, pp. 161-187.

${ }^{54}$ No original: “la massima felicità divisa nel maggior numero". BECCARIA, Cesare. Dei delitti e delle pene. In: BECCARIA, Cesare. Edizione nazionale delle opere di Cesare Beccaria. A cura di Luigi Firpo.
} 
assim, de um utilitarismo político-econômico para um utilitarismo filosófico. ${ }^{55}$

A maior radicalidade do discurso filosófico-político repercutiu-se também sobre as questões jurídicas. Ao invés de uma simples sistematização formal e externa do direito Justiniano, passou-se a aspirar a uma reconstrução do inteiro corpo das leis. A tradição do ius commune deveria ser colocada de lado e as regras da convivência humana deveriam ser reelaboradas integralmente sob a orientação da filosofia. Foi justamente Cesare Beccaria o mais eloquente exemplo desse desejo de superação do ius commune junto com toda a tradição literária que sobre ele foi-se construindo.

Já na abertura de sua principal obra, Dos delitos e das penas, Beccaria ridiculariza o direito europeu continental descrevendo-o como "restos da legislação de um antigo povo conquistador, compilados por ordem de um príncipe que reinou há doze séculos em Constantinopla, misturadas em seguida com os costumes dos longobardos" aos quais ainda se juntariam as opiniões de Carpzow, as práticas indicadas por Claro, os suplícios imaginados por Farinacci.

As desordens dessas leis, que eram "o esgoto de séculos os mais bárbaros", Beccaria as procurava expor "aos diretores da felicidade pública" em um estilo só possível "graças ao doce e esclarecido governo sob o qual vive o autor". Esses “diretores da felicidade pública” eram obviamente "os grandes monarcas, os benfeitores da humanidade que nos regem" e que "amam as verdades expostas pelo obscuro filósofo", isto é, aqueles mesmos príncipes aos quais Muratori tinha endereçado a sua Da Felicidade Pública. Assim, em Beccaria, a solução para os absurdos

Vol. I. Milano: Mediobranca, 1984, pp. 15-129, p. 23. As ideias sensualistas do materialismo iluminista encontraram profícuas reverberações no iluminismo lombardo. Vejam-se a respeito PARENTI, Roberto. Sensismo e edonismo nella cultura lombarda dell'età teresiana. In: DE MADDALENA, Aldo; ROTTELLI, Ettore; BARBARISI, Gennaro (Org.). Economia, istituzioni, cultura in Lombardia nell'età di Maria Teresa. Volume 2: Cultura e Società. Bologna: Società editrice il Mulino, 1982; SINA, Mario. Locke e la filosofia dell'llluminismo lombardo. In: DE MADDALENA, Aldo; ROTTELLI, Ettore; BARBARISI, Gennaro (Org.). Economia, istituzioni, cultura in Lombardia nell'età di Maria Teresa. Volume 2: Cultura e Società. Bologna: Società editrice il Mulino, 1982. Além de Beccaria, Pietro Verri absorveu muitas das ideias de Helvétius e dos materialistas franceses nas suas Meditações sobre a Felicidade, obra de 1765 na qual a máxima utilitarista vem também formulada explicitamente: "Il fine dunque del patto sociale è il ben essere di ciascuno che concorre a formare la società, il che si risolve nella felicità pubblica o sia la maggiore felicità possibile divisa colla maggiore uguaglianza possibile." VERRI, Pietro. Meditazioni sulla felicità. Milano: Feltrinelli, 1997, p. 33.

${ }^{55}$ Sobre o utilitarismo em Beccaria, veja-se CASTRO, Alexander de. 0 utilitarismo de Cesare Beccaria e a eficácia do direito penal no Estado Absolutista. In: ENCONTRO DE HISTÓRIA DO DIREITO: A Construção do Direito Penal e do Processo Penal Modernos. 1., 2008, Florianópolis. Anais eletrônicos. Florianópolis: Fundação Boiteux, 2008, pp. 3-14; FRANCIONI, Gianni. Beccaria filosofo utilitarista. In: ROMAGNOLI, Sergio; PISAPIA, Gian Domenico (Orgs.). Cesare Beccaria tra Milano e l'Europa: convegno di studi per il $250^{\circ}$ anniversario della nascita. Milano: Cariplo-Laterza, 1990, pp. 69-87; ZARONE, Giuseppe. Etica e politica nell'utilitarismo di Cesare Beccaria. Napoli: Istituto Italiano per gli studi storici, 1971. 
das leis não poderia mais ser apenas a prudente correção do direito comum, mas a sua radical substituição por via legislativa visto que nenhum compromisso poderia ser admitido entre os "séculos os mais bárbaros" e os progressos "desse século iluminado e de seus legisladores" 56 . As palavras de Beccaria são um indicativo de como o iluminismo, abordando as mesmas questões, conduzia o reformismo jurídico setecentista a um nível mais alto e intenso de radicalidade.

De certa forma, a posição do iluminismo com relação à reforma do direito refletia a sua posição mais radical com respeito à rejeição da própria sociedade de estamentos da monarquia corporativa do antigo regime. A complexa estrutura jurídica de então, fruto da composição de vários domínios normativos (estatutos citadinos, direito costumeiro, ordenações reais, direito mercantil) que se combinavam, por obra de juristas praxistas de formação universitária, sob o pano de fundo de uma scientia iuris constituída por um direito romano atualizado por seus intérpretes medievais e modernos, era o complemento necessário da complexa sociedade de sociedades $^{57}$ que perdurou com vigor até o fim do século XVIII.

A simplificação e geometrização lógica que dominaram o pensamento jurídico jusracionalista a partir do fim do século XVII e durante todo o século XVIII, por outro lado, apontava em direção a uma sociedade muito mais linear. $\mathrm{Na}$ intersecção mais evidente entre o jurídico e o político, as diversas teorias do contrato social e seu "estado de natureza" representavam o esforço em reconstruir as instituições políticas de modo cartesiano a partir de sua unidade mais básica, que em geral deveria ser o indivíduo e não mais os corpos sociais.

Também o iluminismo reformista procura absorver dentro de seus projetos de desenho

\footnotetext{
56 Vale a pena conferir a emblemática abertura da obra: "Alcuni avanzi di leggi di un antico popolo conquistatore fatte compilare da un principe che dodici secoli fa regnava in Costantinopoli, frammischiate poscia co' riti longobardi, ed involte in farraginosi volumi di privati ed oscuri interpreti, formano quella tradizione di opinioni che da una gran parte dell'Europa ha tuttavia il nome di leggi; ed è cosa funesta quanto comune al dì d'oggi che una opinione di Carpzovio, un uso antico accennato da Claro, un tormento con iraconda compiacenza suggerito da Farinaccio sieno le leggi a cui con sicurezza obbediscono coloro che tremando dovrebbero reggere le vite e le fortune degli uomini. Queste leggi, che sono uno scolo de' secoli i più barbari, sono esaminate in questo libro per quella parte che risguarda il sistema criminale, e i disordini di quelle si osa esporli a' direttori della pubblica felicità con uno stile che allontana il volgo non illuminato ed impaziente. Quella ingenua indagazione della verità, quella indipendenza delle opinioni volgari con cui è scritta quest'opera è un effetto del dolce e illuminato governo sotto cui vive l'autore. I grandi monarchi, $i$ benefattori della umanità che ci reggono, amano le verità esposte dall'oscuro filosofo con un non fanatico vigore, detestato solamente da chi si avventa alla forza o alla industria, respinto dalla ragione; e i disordini presenti da chi ben n'esamina tutte le circostanze sono la satira e il rimprovero delle passate età, non già di questo secolo e de' suoi legislatori." BECCARIA, Cesare. Dei delitti e delle pene. In: BECCARIA, Cesare. Edizione nazionale delle opere di Cesare Beccaria. A cura di Luigi Firpo. Vol. I. Milano: Mediobranca, 1984, pp. 15-129, pp. 17-18.

${ }^{57} \mathrm{~A}$ expressão é de GROSSI, Paolo. Dalla società di società alla insularità dello Stato: fra medioevo ed età moderna. In: GROSSI, Paolo. Società, diritto, stato: un recupero per il diritto. 10 ed., Roma-Bari: Laterza, 2003, pp. 75-95, pp. 75-95.
} 
jurídico da sociedade os elementos básicos dessa nascente sociabilidade moderna de base econômica capitalista e tendente ao liberalismo político em um processo que já foi chamado de o projeto jurídico da modernidade ${ }^{58}$. Essa é talvez a chave para se compreender a radicalidade da rejeição iluminista do ius commune: o direito deveria ser reconstruído desde o início justamente na medida em que a sociedade mesma deveria ser refeita integralmente. ${ }^{59}$

A reforma do direito augurada por Muratori a partir de uma crítica neo-humanista tipicamente italiana ao ius commune, ao ser recebida e radicalizada pela primeira geração de iluministas milaneses, ganhava também em universalidade e, sendo difundida por toda a “republica das letras", tornava-se um projeto mais ou menos comum do século das luzes.

As tentativas mais intensas de realizar o utópico redesenho jurídico da sociedade sobre o qual teorizavam autores iluministas e utilitaristas de fins do século XVIII ocorrerão apenas na abertura do século XIX quando, através da revoluções e agitações liberais, a emergência de novas forças políticas permitirá a proscrição da sociedade corporativa do antigo regime. Só então os poderes políticos ousaram intervir no âmbito do direito privado e, através das novas codificações de direito civil, procuraram reconfigurar os mais básicos fundamentos da interação social entre agentes privados, eliminando distinções estamentais, unificando a personalidade jurídica natural, uniformizando os regimes de propriedade privada, regulando a liberdade contratual sob o regime da autonomia da vontade.

Até então, mesmo os mais intensos exemplos de absolutismo pouco tinham intervindo no âmbito do direito privado. ${ }^{60} 0$ penal foi, ao contrário, o terreno dos experimentos do absolutismo da segunda metade do século XVIII. ${ }^{61}$ De fato, o direito criminal entra muito cedo no radar das reformas absolutistas, movendo-se de uma mera tutela penal dos interesses mais imediatos das autocracias monárquicas - interesses tributários, tarifários e administrativos em geral - até uma perspectiva mais ampla de formação de um poder disciplinar à disposição do soberano no contexto de reformas mais abrangentes. Plenamente considerado como engrenagem

\footnotetext{
${ }^{58}$ COSTA, Pietro. II progetto giuridico: ricerche sulla giurisprudenza del liberalismo classico. Vol. I: Da Hobbes a Bentham. Milano: Giuffrè Editore, 1974.

59 Uma boa análise do radicalismo reformista - e, posteriormente, revolucionário - do iluminismo em KOSELLECK, Reinhart. Crítica e crise. Tradução de Luciana Villas-Boas Castelo-Branco. Rio de Janeiro: UERJ/Contraponto, 1999.

60 O "absolutismo jurídico", portanto, virá apenas depois do absolutismo político. Veja-se sobre isso GROSSI, Paolo. Assolutismo giuridico e diritto privato. Milano: Giuffrè, 1998.

${ }^{61}$ Daniela Frigo, documentando o modesto avanço do absolutismo setecentista sobre o direito privado, que era o domínio por excelência do ius commune, considera a codificação penal como "il segno distintivo della codificazione illuministica." FRIGO, Daniela. Principe, Giudici, Giustizia: Mutamenti Dottrinali e Vicende Istituzionali fra Sei e Settecento. In: COLAO, Floriana; BERLINGER, Luigi (Org.). Illuminismo e Dottrine Penali. Milano: Giuffrè, 1990, pp. 3-38, p. 28.
} 
da organização político-social geral, o sistema penal passa a ser tratado, assim, como capítulo do processo de desenvolvimento do Estado moderno, como local de confronto onde concepções diversas sobre formações políticas e suas interações com a sociedade se contrapunham. ${ }^{62}$

Através da questão penal, Beccaria abordava - em seu Dos delitos e das penas - todo um complexo projeto de reforma radical da sociedade e do Estado representado pelo tardoabsolutismo setecentista. A crítica da ciência jurídica no contexto do discurso da felicidade pública, que foi tão bem representada por Muratori, iria encontrar no direito penal, na medida em que se desenvolvia e se aprofundava agora sob auspícios iluministas, sua primeira grande etapa de implementação.

\section{A PRÁTICA DAS REFORMAS JURÍDICAS SETECENTISTAS: O EMBLEMÁTICO CASO DE PORTUGAL}

Dentre as várias experiências de reforma do direito durante o século XVIII, o caso português ilustra muito bem os desafios práticos implicados na implementação daquelas teorias. Seu cume, ainda que malogrado, foi a tentativa de reformulação completa do direito penal com o projeto de código de Melo Freire, escrito sob inspiração iluminista e beccariana e entregue em 1789 justamente com seu projeto de código de direito público. ${ }^{63}$

Mas o início das reformas jurídicas lusitanas, ao contrário, tiveram - ao menos na aparência - uma índole mais moderada no qual a ideias de Muratori podem ter tido algum papel. De fato, suas ideias não eram completamente desconhecidas em Portugal. Luís António Verney, pensador português que passou a maior parte de sua vida na Itália, não apenas conhecia sua

62 Diz Sbriccoli que o penal se transforma em terreno do conflito político, antes que meramente seu objeto. Veja-se SBRICCOLI, Mario. Beccaria ou l'avènement de l'ordre: le philosophie, les juristes et l'émergence de la question pénale. In: PORRET, Michel. Cesare Beccaria et la culture juridique des lumières: estudes historiques éditée et présentées par Michel Porret. Genève: Librairie Droz S.A., 1997, pp. 178-187, p. 179. Vejam-se também CASTRO, Alexander de. Beccaria e o direito penal do absolutismo esclarecido: O reformismo habsbúrgico e o lluminismo na Lombardia austríaca. In: DE CASTRO, A.; DAL RI JÚNIOR, A.; SONTAG, R.; DE PAULO, A. Iluminismo e Direito Penal. Florianópolis: Fundação Boiteux, 2009, pp. 13-66; CASTRO, Alexander de; DAL RI JÚNIOR, Arno. Iluminismo e absolutismo no modelo jurídico-penal de Cesare Beccaria. Sequiência: estudos jurídicos e políticos. Florianópolis, n. 57, pp. 261 284, dez. 2008.

${ }^{63}$ Sobre o projeto de código criminal de Melo Freire, veja-se HESPANHA, António Manuel. Da "iustitia" à "disciplina": textos, poder e politica penal no Antigo Regime. In: HESPANHA, António Manuel. Justiça e litigiosidade: história e prospectiva. Lisboa: Fundação Calouste Gulbenkian, 1993, pp. 287-379. Veja-se também CASTRO, Alexander de. "Boa Razão" e Codificação Penal: Apontamentos sobre a Questão Penal Setecentista em Portugal (1769-1789). Revista Brasileira de Estudos Políticos. Belo Horizonte, n. 111, pp. 105-143, Jul./Dez. 2015. DOI: 10.9732/P.0034-7191.2016V111P105 
obra, mas com ele trocou cartas no período entre 1745 e $1749 .{ }^{64}$ Em seu Verdadeiro Método de Estudar, Verney dedicou um tópico da Carta XIII, que trata da “Jurisprudencia Romana”, aos "defeitos intrínsecos e extrinsecos da Jurisprudencia", e ainda o complementou com um outro sobre os "defeitos do Direito Canonico intrínsecos, e extrínsecos" incluído na Carta XV, que versa sobre esse ramo do direito. ${ }^{65}$

A ascensão política meteórica de Pombal criou as condições necessárias para a formação de um bloco histórico pró-absolutista liderado por altos funcionários reais e decidido a realizar o ideal do príncipe ativo governante da sociedade. A grande difusão da ciência da polícia e a fundação de uma intendência geral de polícia em $1760^{66}$ dão testemunho da postura proativa da burocracia real, em moldes próximos ao que Muratori havia teorizado anos antes. A própria reforma jurídica não tardaria, assim, a entrar em pauta. Nesse contexto, muito do diagnóstico de Muratori sobre os defeitos da scientia iuris do antigo regime ver-se-ia refletido nos primeiros passos do reformismo jurídico lusitano.

A primeira das historicamente mais relevantes tentativas de domar a ciência jurídica em Portugal, a Lei da boa razão de $1769^{67}$, se esforçou para eliminar os efeitos da interpretação descontrolada estabelecendo um rígido sistema de uniformização da jurisprudência (aqui no

${ }^{64}$ Sobre a troca de cartas entre Muratori e Verney, veja-se MONCADA, Luis Cabral de. Estudos de História do Direito. Século XVIII. Iluminismo Católico. Verney: Muratori. Vol. III. Coimbra: Universidade de Coimbra, 1950.

65 VERNEY, Luís António. Verdadeiro metodo de estudar para ser util à Republica, e à Igreja: proporcionado ao estilo, e necesidade de Portugal. Tomo II. Valensa [Nápoles]: na oficina de Antonio Balle [Genaro e Vicenzo Muzio], 1746, pp. 139-194, 229-252.

${ }^{66}$ Sobre a influência da ciência de polícia em Portugal na época pombalina, vejam-se SEELAENDER, Airton L. Cerqueira Leite. Polizei, Ökonomie und Gesetzgebungslehre. Frankfurt am Main: Vittorio Klostermann, 2003; SEELAENDER, Airton L. Cerqueira Leite. A Polícia e o Rei-Legislador. In: BITTAR, Eduardo C. B. (Org.). História do Direito Brasileiro: Leituras da Ordem Jurídica Nacional. São Paulo: Editora Atlas, 2010b, pp. 120-135; SEELAENDER, Airton L. Cerqueira Leite. "Economia Civil" e "Polícia" no ensino do "Direito Pátrio" em Coimbra: Notas sobre as "Prelecções" de Ricardo Raymundo Nogueira. Tempo: Revista do Departamento de História da UFF. Niterói, vol.17, n. 31, pp.35-63, 2011.

${ }^{67}$ Houve tentativas anteriores, porém de impacto praticamente nulo. Sobre a Lei da boa razão, veja-se CASTRO, Alexander de. Enlightened Absolutism and legal culture in Portugal: rise and decline of legal Pombalism in the 18th century (1769-1789). Zeitschrift der Savigny-Stiftung für Rechtsgeschichte: Germanistische Abteilung. Wien, Köln, Weimar, Volume 133, pp. 296-364, 2016, pp. 309-29; ANTUNES, Álvaro de Araújo. Pelo rei, com razão: comentários sobre as reformas pombalinas no campo jurídico. Revista do Instituto Histórico e Geográfico Brasileiro. Rio de Janeiro, Ano 172, n. 452, pp. 15-50, 2011; MERÊA, M. Paulo. Direito romano, direito comum e boa razão. Boletim da Faculdade de Direito da Universidade de Coimbra. Coimbra, v. 16, pp. 539-543, 1940; WEHLING, Arno; WEHLING, Maria José Mesquita Cavalleiro de Macedo. Despotismo Ilustrado e Uniformização Legislativa: O Direito Comum nos Períodos Pombalino e Pós-Pombalino. Revista da Faculdade de Letras. Historia. Porto, n. 14, pp. 413-428, 1997; FALCON, Francisco José Calazans. As práticas do reformismo ilustrado pombalino no campo jurídico. Revista de História das Ideias. Coimbra, vol. 18, pp. 511-527, 1996; SILVA, Nuno Espinosa Gomes da. História do direito português: fontes de direito. Lisboa: Gulbenkian, 1991, pp. 362ss.; MARCOS, Rui Manuel de Figueiredo. A legislação pombalina: alguns aspectos fundamentais. 2. ed. Coimbra: Almedina, 2006, pp. 163ss. 
MURATORI E OS DEFEITOS DA JURISPRUDÊNCIA: CONSIDERAÇÕES SOBRE OS FUNDAMENTOS TEÓRICOS DAS REFORMAS JURÍDICAS SETECENTISTAS

ALEXANDER DE CASTRO

sentido de decisões judiciais). Assim dizia-se lá que dúvidas sobre a correta interpretação das leis seriam decididas apenas por Assentos ${ }^{68}$ emitidos ou, pelo menos, aprovados exclusivamente pela Casa da Suplicação, a mais alta corte portuguesa de então. ${ }^{69}$ Os advogados das partes poderiam levantar dúvidas sobre a correta interpretação da lei, que seriam então resolvidas por um Assento, mas seriam punidos caso usassem "raciocínios frívolos" para confundir o sentido das leis. $^{70}$

Reduzia-se, portanto, o número de intérpretes com poder vinculante e coibia-se a criatividade sofística dos advogados. A Lei da boa razão também baniu das cortes as glosas e opiniões de Bártolo, Acúrsio e “outros semelhantes Doutores da mesma Escola". ${ }^{71} 0$ que se bania aqui, na verdade, era a força normativa da jurisprudência doutoral - a opinião que se substitui à lei, na fórmula de Muratori - à qual se deu justamente o nome de bartolismo. As diversas

${ }^{68}$ Sobre os Assentos, veja-se TUCCI, José Rogério Cruz e. Tradição luso-brasileira dos assentos da Casa da Suplicação. In: BITTAR, Eduardo C. B. (Org.). História do Direito Brasileiro: Leituras da Ordem Jurídica Nacional. São Paulo: Editora Atlas, 2010, pp. 81-101; CRUZ, Guilherme Braga da. O direito subsidiário na história do direito português. In: CRUZ, Guilherme Braga da. Obras Esparsas. Volume II: estudos de história do direito: direito moderno, $2^{\text {a }}$ parte. Coimbra: Coimbra Editora, 1981b, pp. 145-436, pp. 391-9; MERÊA, M. Paulo. Resumo das Lições de História do Direito Português: Feitas no ano lectivo de 19241925. Coimbra: Universidade de Coimbra, 1925, pp. 145-6; MARCOS, Rui, 2006, pp. 205-6, 271ss., 280s., 295ss. Veja-se também SCHOLZ, Johannes-Michael. Literaturgeschichtliche und vergleichende Anmerkungen zur portugiesischen Rechtsprechung im Ancien Régime. Revista Portuguesa de História. Coimbra, vol. XIV, pp.95-159, 1974; CRUZ, Guilherme Braga da. Formação histórica do moderno direito privado português e brasileiro. In: CRUZ, Guilherme Braga da. Obras Esparsas. Volume II: estudos de história do direito: direito moderno, $1^{\text {a }}$ Parte, Coimbra, Coimbra Editora, 1981a, pp. 25-75.

${ }^{69}$ Vejam-se os itens 1, 2, 4, 5, 6, 7, 8 e 14 da Lei da boa razão em PORTUGAL. Lei de 18 de Agosto de 1769. Declarando a authoridade do Direito Romano, e Canonico, Assentos, Estylos, e Costumes. In: ALMEIDA, Cândido Mendes de. Codigo Philippino ou Ordenações e Leis do Reino de Portugal recopiladas por mandado d'El-Rey D. Philippe I. 14. ed. Rio de Janeiro: Tipografia do Instituto Filomático, 1870, pp. 725-30, pp. 726-7, 730. Sobre esse assunto, veja-se CASTRO, Alexander de. Enlightened Absolutism and legal culture in Portugal: rise and decline of legal Pombalism in the 18th century (1769-1789). Zeitschrift der Savigny-Stiftung für Rechtsgeschichte: Germanistische Abteilung. Wien, Köln, Weimar, Volume 133, pp. 296-364, 2016, pp. 312-317.

70 Veja-se o item 7 da Lei da boa razão em PORTUGAL. Lei de 18 de Agosto de 1769. Declarando a authoridade do Direito Romano, e Canonico, Assentos, Estylos, e Costumes. In: ALMEIDA, Cândido Mendes de. Codigo Philippino ou Ordenações e Leis do Reino de Portugal recopiladas por mandado d'El-Rey D. Philippe I. 14. ed. Rio de Janeiro: Tipografia do Instituto Filomático, 1870, pp. 725-30, p. 727. Sobre esse assunto, veja-se CASTRO, Alexander de. Enlightened Absolutism and legal culture in Portugal: rise and decline of legal Pombalism in the 18th century (1769-1789). Zeitschrift der Savigny-Stiftung für Rechtsgeschichte: Germanistische Abteilung. Wien, Köln, Weimar, Volume 133, pp. 296-364, 2016, pp. 314-5.

71 Veja-se o item 13 da Lei da boa razão em PORTUGAL. Lei de 18 de Agosto de 1769. Declarando a authoridade do Direito Romano, e Canonico, Assentos, Estylos, e Costumes. In: ALMEIDA, Cândido Mendes de. Codigo Philippino ou Ordenações e Leis do Reino de Portugal recopiladas por mandado d'El-Rey D. Philippe I. 14. ed. Rio de Janeiro: Tipografia do Instituto Filomático, 1870, pp. 725-30, pp. 729-30. Sobre esse assunto, veja-se CASTRO, Alexander de. Enlightened Absolutism and legal culture in Portugal: rise and decline of legal Pombalism in the 18th century (1769-1789). Zeitschrift der Savigny-Stiftung für Rechtsgeschichte: Germanistische Abteilung. Wien, Köln, Weimar, Volume 133, pp. 296-364, 2016, pp. 317-8. 
opiniões privadas não poderiam mais, portanto, se substituir à lei. Também ficava prejudicada, assim, a communis opinio doctorum. ${ }^{72}$

Em 1772, com a reforma do ensino jurídico, mais um passo seria dado, procurando-se dentre outras coisas - estimular a sistematização doutrinária do direito romano. ${ }^{73}$ Se faltou um intervento direto do monarca a fim de organizar o material jurídico romanístico com um novo código - como havia proposto Muratori - não deixa de ser claro que a tentativa de disciplinar a ciência jurídica lusitana indicava uma interpretação em comum de seus defeitos.

\section{CONCLUSÃO}

As teorias da reforma do direito que dominaram durante a segunda metade do século XVIII e influenciaram profundamente a atuação de monarcas como José II da Áustria, Pedro Leopoldo da Toscana e José I (ou de fato, Marquês de Pombal) de Portugal foram, em larga medida, produto da crítica iluminista da sociedade do antigo regime. Uma crítica que via no ius commune um dos pilares da irracionalidade da própria sociedade de então. Mas a versão original da concepção de uma reforma jurídica confiada a príncipes benevolentes, combinada com ásperas críticas à scientia iuris do antigo regime, já havia vindo a lume pela pena de Lodovico Antonio Muratori.

\footnotetext{
72 Sobre as relações entre Bártolo, Acúrsio e a communis opinio doctorum in Portugal, bem como sobre os vários critérios que prevaleceram ao longo do tempo na determinação da communis opinio, veja-se CRUZ, Guilherme Braga da. 0 direito subsidiário na história do direito português. In: CRUZ, Guilherme Braga da. Obras Esparsas. Volume II: estudos de história do direito: direito moderno, $2^{\mathrm{a}}$ parte. Coimbra: Coimbra Editora, 1981b, pp. 145-436, pp. 365-82. Veja-se também SILVA, Nuno José Espinosa Gomes da. Bártolo na História do Direito Português. Revista da Faculdade de Direito da Universidade de Lisboa. Lisboa, vol. XII, pp. 177-221, 1960; veja-se também COSTA, Mário Júlio de Almeida. Romanisme et bartolisme dans le droit portugais. In: SEGOLONI, Danilo (Org.). Bartolo da Sassoferrato: Studi e documenti per il VI centenário. Volume I. Milano:, Giuffré, 1962, pp. 313-334; COSTA, Mário Júlio de Almeida. La presence d'Accurse dans l'histoire du droit portugais. Boletim da Faculdade de Direito. Coimbra, n. 41, pp. 47-62, 1965. Sobre as relações entre literatura jurídica e prática jurisdicional em Portugal, veja-se SCHOLZ, Johannes-Michael. Literaturgeschichtliche und vergleichende Anmerkungen zur portugiesischen Rechtsprechung im Ancien Régime. Revista Portuguesa de História. Coimbra, vol. XIV, pp.95-159, 1974, pp. $112-3$ e 138 ss.

73 Sobre a reforma do ensino jurídico nos estatutos pombalinos, veja-se CASTRO, Alexander de. Enlightened Absolutism and legal culture in Portugal: rise and decline of legal Pombalism in the 18th century (1769-1789). Zeitschrift der Savigny-Stiftung für Rechtsgeschichte: Germanistische Abteilung. Wien, Köln, Weimar, Volume 133, pp. 296-364, 2016, pp. 330-52; COSTA, Mário Júlio de Almeida; MARCOS, Rui de Figueiredo. A reforma pombalina dos estudos jurídicos. In ARAÚJO, Ana Cristina (Org.). O Marquês de Pombal e a Universidade. Coimbra: Imprensa da Universidade, 2000, pp. 97-125; HESPANHA, António Manuel. Forma e valores nos estatutos pombalinos da universidade (1772). In: HESPANHA, António Manuel. A história do direito na história social. Lisboa: Livros Horizonte, 1978, pp. 150-168; GAUER, Ruth Maria Chittó. A modernidade portuguesa e a Reforma Pombalina de 1772. Porto Alegre: EDIPUCRS, 1996, pp. 63-86; CAETANO, Marcello. História do direito português (1140-1495). 3. Ed. Lisboa: Verbo, 1992, 35-41.
} 
Com um arsenal teórico de base neohumanista e orientação geral relativamente moderada, foi Muratori que formulou alguns dos tópicos destinados a reverberar persistentemente por toda a "república das letras" do século das luzes. Suas ideias sobre a monarquia benevolente e a correção dos defeitos da jurisprudência por intervento monárquico foram uma fonte de inspiração para a geração de iluministas milaneses que emergiria pouco mais de uma década depois de sua morte, dentre os quais encontrava-se Cesare Beccaria, o grande teórico da reforma penal setecentista. Mesmo em Portugal, suas ideias reverberariam na pena de expoentes do iluminismo lusitano, como Luís António Verney, e ajudariam assim a compor o diagnóstico dos problemas jurídicos que orientaram os primeiros passos das reformas pombalinas do direito.

\section{REFERÊNCIAS}

ANTUNES, Álvaro de Araújo. Pelo rei, com razão: comentários sobre as reformas pombalinas no campo jurídico. Revista do Instituto Histórico e Geográfico Brasileiro. Rio de Janeiro, Ano 172, n. 452, pp. 15-50, 2011.

BECCARIA, Cesare. Dei delitti e delle pene. In: BECCARIA, Cesare. Edizione nazionale delle opere di Cesare Beccaria. A cura di Luigi Firpo. Vol. I. Milano: Mediobranca, 1984, pp. 15-129.

CAETANO, Marcello. História do direito português (1140-1495). 3. Ed. Lisboa: Verbo, 1992, 3541.

CAPRA, Carlo. Il gruppo del "Caffè" e le riforme. In: FERRONE, Vincenzo; FRANCIONI, Gianni (Org.). Cesare Beccaria: La pratica dei lumi. Atti del Convegno. Firenze: Leo S. Olschki Editore, 2000, pp. 63-78.

CAPRA, Carlo. Lo sviluppo delle riforme asburgiche nello Stato di Milano. In: SCHIERA, Pierangelo. La dinâmica statale austríaca nel XVIII e XIX secolo. Bologna: Società editrice il Mulino, 1981, pp. 161-187.

CASTRO, Alexander de. Beccaria e o direito penal do absolutismo esclarecido: 0 reformismo habsbúrgico e o lluminismo na Lombardia austríaca. In: DE CASTRO, A.; DAL RI JÚNIOR, A.; SONTAG, R.; DE PAULO, A. Iluminismo e Direito Penal. Florianópolis: Fundação Boiteux, 2009, pp. 13-66.

CASTRO, Alexander de. "Boa Razão" e Codificação Penal: Apontamentos sobre a Questão Penal Setecentista em Portugal (1769-1789). Revista Brasileira de Estudos Políticos. Belo Horizonte, n. 111, pp. 105-143, Jul./Dez. 2015. Disponível em:

https://pos.direito.ufmg.br/rbep/index.php/rbep/article/view/P.0034-7191.2016V111P105/0. Acesso em: 26 mar. 2018. DOI: https://doi.org/10.9732/P.0034-7191.2016V111P105 
CASTRO, Alexander de. Enlightened Absolutism and legal culture in Portugal: rise and decline of legal Pombalism in the 18th century (1769-1789). Zeitschrift der Savigny-Stiftung für Rechtsgeschichte: Germanistische Abteilung. Wien, Köln, Weimar, Volume 133, pp. 296-364, 2016. Disponível em: https://www.degruyter.com/view/j/zrgga.2016.133.issue-1/zrgga-20160108/zrgga-2016-0108.xml. Acesso em: 26 mar. 2018. DOI: 10.7767/zrgga-2016-0108

CASTRO, Alexander de. 0 utilitarismo de Cesare Beccaria e a eficácia do direito penal no Estado Absolutista. In: ENCONTRO DE HISTÓRIA DO DIREITO: A Construção do Direito Penal e do Processo Penal Modernos. 1., 2008, Florianópolis. Anais eletrônicos. Florianópolis: Fundação Boiteux, 2008, pp. 3-14.

CASTRO, Alexander de; DAL RI JÚNIOR, Arno. Iluminismo e absolutismo no modelo jurídico-penal de Cesare Beccaria. Sequiência: estudos jurídicos e políticos. Florianópolis, n. 57, pp. 261-284, dez. 2008. Disponível em: https://periodicos.ufsc.br/index.php/sequencia/article/view/14958. Acesso em: 26 mar. 2018. DOI: https://doi.org/10.5007/2177-7055.2008v29n57p261

COING, Helmut. Europäisches Privatrecht. vol. I: Älteres gemeines Recht. München: C. H. Beck'sche Verlagsbuchhandlung, 1985.

COSTA, Mário Júlio de Almeida. La presence d'Accurse dans l'histoire du droit portugais. Boletim da Faculdade de Direito. Coimbra, n. 41, pp. 47-62, 1965.

COSTA, Mário Júlio de Almeida. Romanisme et bartolisme dans le droit portugais. In: SEGOLONI, Danilo (Org.). Bartolo da Sassoferrato: Studi e documenti per il VI centenário. Volume I. Milano:, Giuffré, 1962, pp. 313-334.

COSTA, Mário Júlio de Almeida; MARCOS, Rui de Figueiredo. A reforma pombalina dos estudos jurídicos. In: ARAÚJO, Ana Cristina (Org.). O Marquês de Pombal e a Universidade. Coimbra: Imprensa da Universidade, 2000, pp. 97-125.

COSTA, Pietro. Il progetto giuridico: ricerche sulla giurisprudenza del liberalismo classico. Vol. I: Da Hobbes a Bentham. Milano: Giuffrè Editore, 1974.

CRUZ, Guilherme Braga da. Formação histórica do moderno direito privado português e brasileiro. In: CRUZ, Guilherme Braga da. Obras Esparsas. Volume II: estudos de história do direito: direito moderno, $1^{\text {a }}$ Parte, Coimbra, Coimbra Editora, 1981a, pp. 25-75.

CRUZ, Guilherme Braga da. O direito subsidiário na história do direito português. In: CRUZ, Guilherme Braga da. Obras Esparsas. Volume II: estudos de história do direito: direito moderno, $2^{a}$ parte. Coimbra: Coimbra Editora, 1981b, pp. 145-436.

DARRICAU, Raymond. Le Prince chrétien dans la pensée de Lodovico Antonio Muratori. In: LA FORTUNA DI L. A. MURATORI: Atti del convegno internazionale di studi muratoriani, 1972, Modena. Anais impressos. Firenze, Olschki, 1975, pp. 331-47.

DONATI, Benvenuto. La critica del Muratori alla giurisprudenza. Modena: Pubblicazioni della Facoltà di Giurisprudenza presso l’Università degli Studi, 1934.

DONATI, Benvenuto. Lodovico Antonio Muratori e la giurisprudenza del suo tempo. Modena: Pubblicazioni della Facoltà di Giurisprudenza presso l'Università degli Studi, 1931. 
DONATI, Benvenuto. Storia critica del De Codice Carolino. In: MURATORI, Lodovico Antonio. Scritti giuridici complementari del trattato del 1742 "Dei difetti della giurisprudenza". I. De Codice Carolino II. Pareri legali. Testi inediti con annotazione a cura di Benvenuto Donati. Modena: Società Tipografica Modenese, 1942, pp. 53-75.

FALCO, Giorgio. L. A. Muratori e il preilluminismo. In: FUBINI, Mario. La cultura illuministica in Italia. Torino: ERI,1957, pp. 23-41.

FALCON, Francisco José Calazans. As práticas do reformismo ilustrado pombalino no campo jurídico. Revista de História das Ideias. Coimbra, vol. 18, pp. 511-527, 1996.

FRANCIONI, Gianni. Beccaria filosofo utilitarista. In: ROMAGNOLI, Sergio; PISAPIA, Gian Domenico (Orgs.). Cesare Beccaria tra Milano e l'Europa: convegno di studi per il $250^{\circ}$ anniversario della nascita. Milano: Cariplo-Laterza, 1990, pp. 69-87.

FREDERICO II. O Anti-Maquiavel. Tradução de Ivone C. Benedetti. São Paulo: WMF Martins Fontes, 2014.

FRIGO, Daniela. Disciplina rei familiariae: a economia como modelo administrativo de Ancien Régime. Penélope: revista de história e ciências sociais. Lisboa, n. 6, pp. 47-62, 1991.

FRIGO, Daniela. Il padre di famiglia: governo della casa e governo civile nella tradizione dell'“econômica” tra cinque e seicento. Roma: Bulzoni Editore, 1985.

FRIGO, Daniela. Principe, Giudici, Giustizia: Mutamenti Dottrinali e Vicende Istituzionali fra Sei e Settecento. In: COLAO, Floriana; BERLINGER, Luigi (Org.). Illuminismo e Dottrine Penali. Milano: Giuffrè, 1990, pp. 3-38.

GAUER, Ruth Maria Chittó. A modernidade portuguesa e a Reforma Pombalina de 1772. Porto Alegre: EDIPUCRS, 1996, pp. 63-86.

GROSSI, Paolo. Assolutismo giuridico e diritto privato. Milano: Giuffrè, 1998.

GROSSI, Paolo. Dalla società di società alla insularità dello Stato: fra medioevo ed età moderna. In: GROSSI, Paolo. Società, diritto, stato: un recupero per il diritto. 10 ed., Roma-Bari: Laterza, 2003, pp. 75-95.

HESPANHA, António Manuel. Da “iustitia” à “disciplina”: textos, poder e politica penal no Antigo Regime. In: HESPANHA, António Manuel. Justiça e litigiosidade: história e prospectiva. Lisboa: Fundação Calouste Gulbenkian, 1993, pp. 287-379.

HESPANHA, António Manuel. Forma e valores nos estatutos pombalinos da universidade (1772). In: HESPANHA, António Manuel. A história do direito na história social. Lisboa: Livros Horizonte, 1978, pp. 150-168.

KOSELLECK, Reinhart. Crítica e crise. Tradução de Luciana Villas-Boas Castelo-Branco. Rio de Janeiro: UERJ/Contraponto, 1999. 
LUIG, Klaus. Samuel Stryk (1640-1710) und der usus modernus pandectarum. In: LUIG, Klaus. Römisches Recht, Naturrecht, nationales Recht. Goldbach: Keip, 1998, pp. 91-107.

MARCOS, Rui Manuel de Figueiredo. A legislação pombalina: alguns aspectos fundamentais. 2. ed. Coimbra: Almedina, 2006.

MARONGIU, Antonio. La scienza del diritto penale nei secc.XVI-XVIII. In: La formazione storica del diritto moderno in Europa. Atti del III congresso internazionale della Società italiana di storia del diritto. Tomo I. Firenze: Leo S. Olschki Editore, 1977, pp. 409-429.

MATTEI, Rodolfo De. Dal premachiavellismo all'antimachiavellismo. Firenze: G.C. Sansoni, 1969.

MEREAA, M. Paulo. Direito romano, direito comum e boa razão. Boletim da Faculdade de Direito da Universidade de Coimbra. Coimbra, v. 16, pp. 539-543, 1940.

MERÊA, M. Paulo. Resumo das Lições de História do Direito Português: Feitas no ano lectivo de 1924-1925. Coimbra: Universidade de Coimbra, 1925.

MOELLER, Ernst von. Julius Clarus aus Alessandria, der Kriminalist des 16. Jahrhunderts, der Rat Philipps II. 1525-1575. Aalen: Scientia Verlag, 1977.

MONCADA, Luis Cabral de. Estudos de História do Direito. Século XVIII. Iluminismo Católico. Verney: Muratori. Vol. III. Coimbra: Universidade de Coimbra, 1950.

MOR, Carlo Guido. L. A. Muratori fra interpreti e codificazione. Modena: Società Tipografica Modenese, 1942.

MURATORI, Lodovico Antonio. De Codice Carolino. In: DONATI, Benvenuto. Lodovico Antonio Muratori e la giurisprudenza del suo tempo. Modena: Pubblicazioni della Facoltà di Giurisprudenza presso l'Università degli Studi, 1935, pp. 173-209.

MURATORI, Ludovico Antonio. Dei difetti della giurisprudenza. Venezia: Presso Giambattista Pasquali, 1747.

MURATORI, Ludovico Antonio. Della pubblica felicità: oggetto de' buoni prìncipi. Roma: Donzelli Editore, 1996.

MURATORI, Ludovico Antonio. Delle riflessioni sopra il buon gusto. 2. Parte. Venezia: Nicolò Pezzana, 1717.

PARENTI, Roberto. Sensismo e edonismo nella cultura lombarda dell'età teresiana. In: DE MADDALENA, Aldo; ROTTELLI, Ettore; BARBARISI, Gennaro (Org.). Economia, istituzioni, cultura in Lombardia nell'età di Maria Teresa. Volume 2: Cultura e Società. Bologna: Società editrice il Mulino, 1982.

PATTARO, Enrico. I difetti della giurisprudenza di Muratori. Rivista internazionale di filosofia del diritto. Milano, série IV, n. 50, pp. 88-144, 1973. 
PATTARO, Enrico. Il buon legislatore e il buon interprete nella prospettiva del reformismo metodologico di L. A. Muratori. In: ZUCCHINI, Giampaolo. L'Educazione Giuridica. V. Modelli di legislatore e scienza della legislazione, Tomo I: Filosofia e scienza della legislazione. Napoli: Edizioni scientifiche Italiane, 1988, pp. 157-178.

PATTARO, Enrico. Il pensiero giuridico di L. A. Muratori tra metodologia e politica. Milano: Giuffrè, 1974.

PORTUGAL. Lei de 18 de Agosto de 1769. Declarando a authoridade do Direito Romano, e Canonico, Assentos, Estylos, e Costumes. In: ALMEIDA, Cândido Mendes de. Codigo Philippino ou Ordenações e Leis do Reino de Portugal recopiladas por mandado d'El-Rey D. Philippe I. 14. ed. Rio de Janeiro: Tipografia do Instituto Filomático, 1870, pp. 725-30.

RANIERI, Filippo. Entscheidungsfindung und Technik der Urteilsredaktion in der Tradition des deutschen Usus Modernus: das Beispiel der Aktenrelationen am Reichskammergericht. In: WIJFFELS, Alain (Org.). Case Law in the Making: The Techniques and Methods of Judicial Records and Law Reports. Vol. 1. Berlin: Duncker und Humblot, 1997, pp. 277-297.

RE, Niccolò Del. Prospero Farinacci, Giureconsulto Romano (1544-1618). Roma: Fondazione Marco Besso, 1999.

RICUPERATI, Giuseppe. Il pensiero politico degli illuministi. In: FIRPO, Luigi (Org.). Storia delle idee politiche, economiche e sociali. Torino: Utet, 1975, pp. 245-402.

ROBERTI, Melchiorre. Lodovico Antonio Muratori e il tramonto del diritto comune. Rivista storica di diritto italiano. Bologna, n. 9, pp. 12-36, 1936.

SANTOS, Cândido dos. "Matrizes do Iluminismo católico da época Pombalina." In: SILVA, Francisco Ribeiro da. Estudos em Homenagem a Luís António de Oliveira Ramos. Volume I. Porto: Faculdade de Letras da Universidade do Porto. 2004. pp 949-956.

SBRICCOLI, Mario. Beccaria ou l'avènement de l'ordre: le philosophie, les juristes et l'émergence de la question pénale. In: PORRET, Michel. Cesare Beccaria et la culture juridique des lumières: estudes historiques éditée et présentées par Michel Porret. Genève: Librairie Droz S.A., 1997, pp. 178-187.

SBRICCOLI, Mario. L'interpretazione dello statuto: contributo allo studio della funzione dei giuristi nell'età comunale. Milano: A. Giuffrè, 1969.

SCHIERA, Pierangelo. Il cameralismo e l'assolutismo tedesco: Dall'arte di governo alle scienze dello Stato. Milano: A. Giuffre, 1968.

SCHOLZ, Johannes-Michael. Literaturgeschichtliche und vergleichende Anmerkungen zur portugiesischen Rechtsprechung im Ancien Régime. Revista Portuguesa de História. Coimbra, vol. XIV, pp.95-159, 1974.

SCHRÖDER, Jan. Recht als Wissenschaft: Geschichte der juristischen Methodenlehre in der Neuzeit (1500-1933). 2. Ed. München: Beck, 2012.

SCHULZE, Reiner. Policey und Gesetzgebungslehre im 18. Jahrhundert. Berlin: Duncker \& Humblot, 1982. 
SEELAENDER, Airton L. Cerqueira Leite. "Economia Civil" e "Polícia” no ensino do "Direito Pátrio" em Coimbra: Notas sobre as "Prelecções" de Ricardo Raymundo Nogueira. Tempo: Revista do Departamento de História da UFF. Niterói, vol.17, n. 31, pp.35-63, 2011.

SEELAENDER, Airton L. Cerqueira Leite. A “Polícia” e as Funções do Estado: Notas sobre a "Polícia" do Antigo Regime. Revista da Faculdade de Direito. Universidade Federal do Paraná, v. 49, p. 73-87, 2010a.

SEELAENDER, Airton L. Cerqueira Leite. A Polícia e o Rei-Legislador. In: BITTAR, Eduardo C. B. (Org.). História do Direito Brasileiro: Leituras da Ordem Jurídica Nacional. São Paulo: Editora Atlas, 2010b, pp. 120-135.

SEELAENDER, Airton L. Cerqueira Leite. Polizei, Ökonomie und Gesetzgebungslehre. Frankfurt am Main: Vittorio Klostermann, 2003;

SILVA, Nuno Espinosa Gomes da. História do direito português: fontes de direito. Lisboa: Gulbenkian, 1991.

SILVA, Nuno José Espinosa Gomes da. "Bártolo na História do Direito Português". Revista da Faculdade de Direito da Universidade de Lisboa. Lisboa, vol. XII, pp. 177-221, 1960.

SINA, Mario. Locke e la filosofia dell'Illuminismo lombardo. In: DE MADDALENA, Aldo; ROTTELLI, Ettore; BARBARISI, Gennaro (Org.). Economia, istituzioni, cultura in Lombardia nell'età di Maria Teresa. Volume 2: Cultura e Società. Bologna: Società editrice il Mulino, 1982.

SORBELLI, Tommaso. Nel bicentenario della pubblicazione dei "Difetti della Giurisprudenza" di L. A. Muratori. Studi e documenti. Reggio Emilia, n. XXI, vol. II, pp. 258- 272, 1943.

SORBELLI, Tommaso. Nel bicentenario della pubblicazione della "Pubblica felicita". Atti e Memorie della R. Deputazione di Storia Patria per le Antiche Provincie Modenesi. Modena, Série VIII, vol. II, pp. 239-255, 1949.

STOLLEIS, Michael. Geschichte des öffentlichen Rechts in Deutschland. Band 1: Reichspublizistik und Policeywissenschaft 1600 bis 1800. München: Beck, 1988.

TARDINI, Luigi Vincenzo. I fondamenti della concezione giuridica di L. A. Muratori: Studi sul trattato «La Filosofia Morale». Modena: Società tipografica modenese, 1937.

TARELLO, Giovanni. Storia della cultura giuridica moderna: assolutismo e codificazione del diritto. Bologna: Società editrice il Mulino, 1999.

TUCCI, José Rogério Cruz e. Tradição luso-brasileira dos assentos da Casa da Suplicação. In: BITTAR, Eduardo C. B. (Org.). História do Direito Brasileiro: Leituras da Ordem Jurídica Nacional. São Paulo: Editora Atlas, 2010, pp. 81-101.

VECCHI, Alberto. Nota sul riformismo di Muratori. Rassegna italiana di politica e di cultura. Roma, n. 315, pp. 76-89, fevereiro 1951.

VENTURI, Franco. Settecento riformatore. Volume I: Da Muratori a Beccaria (1730-1764). Torino: Einaudi, 1987. 
VERNEY, Luís António. Verdadeiro metodo de estudar para ser util à Republica, e à Igreja: proporcionado ao estilo, e necesidade de Portugal. Tomo II. Valensa [Nápoles]: na oficina de Antonio Balle [Genaro e Vicenzo Muzio], 1746.

VERRI, Pietro. Meditazioni sulla felicità. Milano: Feltrinelli, 1997.

VOPPEL, Reinhard. Der Einfluß des Naturrechts auf den usus modernus: Eine Untersuchung anhand der Literatur zum geltenden Recht im 17. und 18. Jahrhundert. Köln: Heymann, 1996.

WEBER, Max. Economia e Sociedade. Vol. 2. Tradução de Regis Barbosa e Karen Elsabe Barbosa. Brasília: Editora Universidade de Brasília; São Paulo: Imprensa Oficial do Estado de São Paulo, 1999.

WEHLING, Arno; WEHLING, Maria José Mesquita Cavalleiro de Macedo. Despotismo Ilustrado e Uniformização Legislativa: O Direito Comum nos Períodos Pombalino e Pós-Pombalino. Revista da Faculdade de Letras. História. Porto, n. 14, pp. 413-428, 1997.

WIEACKER, Franz. Privatrechtsgeschichte der Neuzeit: unter besonderer Berücksichtigung der deutschen Entwicklung. Göttingen: Vandenhoeck \& Ruprecht, 1967.

WILLOWEIT, Dietmar. Der Usus modernus oder die geschichtliche Begründung des Rechts. Zur rechtstheoretischen Bedeutung des Methodenwandels im späten 17. Jahrhundert. In:

WILLOWEIT, Dietmar (Org.). Die Begründung des Rechts als historisches Problem. München: Oldenbourg Verlag, 2000, pp. 229-246.

WOOLF, Stuart J.; CARACCIOLO, Alberto; BADALONI, Nicola; VENTURI, Franco. Storia d'Italia. Vol. 3: Dal primo Settecento all'Unità. Torino: Giulio Einaudi editore, 1978.

ZARONE, Giuseppe. Etica e politica nell'utilitarismo di Cesare Beccaria. Napoli: Istituto Italiano per gli studi storici, 1971.

Recebido em: 26.03.2018 / Revisões requeridas em: 24.05.2019 / Aprovado em: 21.06.2019 / Publicado em: 20.07.2019

\section{COMO FAZER REFERÊNCIA AO ARTIGO (ABNT):}

CASTRO, Alexander de. Muratori e os defeitos da jurisprudência: considerações sobre os fundamentos teóricos das reformas jurídicas setecentistas. Revista Eletrônica do Curso de Direito da UFSM, Santa Maria, RS, v. 14, n. 2, e31837, maio./ago. 2019. ISSN 1981-3694. DOI: http://dx.doi.org/10.5902/1981369431837. Disponível em: https://periodicos.ufsm.br/revistadireito/article/view/31837 Acesso em: dia mês. ano.

Direitos autorais 2019 Revista Eletrônica do Curso de Direito da UFSM

Editores responsáveis: Rafael Santos de Oliveira e Angela Araujo da Silveira Espindola

Esta obra está licenciada com uma Licença Creative Commons Atribuição-NãoComercial-SemDerivações 4.0 Internacional. 
ISSN 1981-3694

(DOI): $10.5902 / 1981369431837$

\section{SOBRE O AUTOR}

\section{ALEXANDER DE CASTRO}

Doutor em Teoria e História do Direito pela Università degli Studi di Firenze (Florença, Itália). Pós-doutorado pela Westfälische Wilhelms Universität Münster (Alemanha) e pela Freie Universität Berlin (Alemanha) Possui mestrado em Teoria e Filosofia do Direito pela Universidade Federal de Santa Catarina (UFSC) e graduação em Direito pela Universidade Estadual de Maringá (UEM). Foi pesquisador visitante no Centro di Studi per la Storia del Pensiero Giuridico Moderno da Università degli Studi di Firenze, no Institut für Rechtsgeschichte e no Exzellenzcluster Religion und Politik in den Kulturen der Vormoderne und der Moderne, ambos da Westfälische Wilhelms -Universität Münster (Alemanha), bem como no Lateinamerika -Institut da Freie Universität Berlin (Alemanha). Também foi resident fellow do Polish Institute of Advanced Studies da Academia de Ciências da Polônia. Trabalhou como pesquisador (wissenschaftlicher Mitarbeiter) no Institut für Rechtsgeschichte da Westfälische Wilhelms- Universität Münster. Foi professor substituto na Universidade Federal de Santa Catarina. Atualmente é professor dos cursos de graduaçãos e de mestrado em Ciências Jurídicas da UniCesumar. Também leciona na graduação em Direito da UniFatecie. Realiza pesquisas na área de História do Direito, com ênfase sobretudo em História do Direito Penal. 